\title{
تحليل أثر الموازية العامة على الفقر في عينة من الدول للمدة *(2015-2000)
}

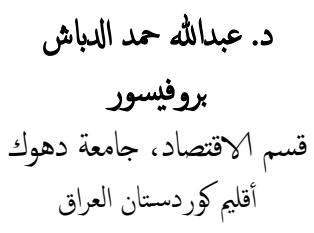

\author{
نوزان ممد صالخ \\ مدرس مساعد \\ قسم الاقتصاد، جامعة نوروز \\ أقنيم كوردستان العراق توات نوروز
}

الملخص

استهدف هذا البحث التعرف على ثثر الموانة العامة على مؤشرات النقر الموجودة في دول عينة البحث المنكونة من ست دول نامية( برازيل، اندويسيا، أوكرانيا، بوليفيا، هندوراس، زامبيا) وخلال الغنزة



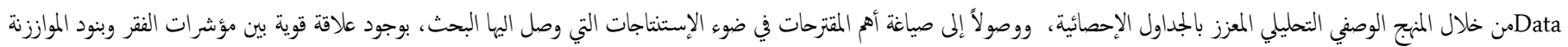

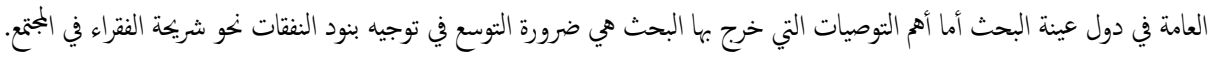
الكلمات المالة: الموازنة العامة، الفتر ، Panel Data، اختبار ARDL.

1

على الرغ من قالة البحوث التي تربط بين الموازنات العامة للدول وقضية الفتر الموجود 2. أهية البحث فيها وعدم الربط بين هذه المتغيرات في دول أخرى، إلا أنه يمكن بيان أثز الموازنة العامة تأتي أهمية البحث من خلال ماتتصف به عملية أداء الموازنة العامة في الدول النامية سواء بشكل مباشر او غير مباشر على حياة الفقراء من خلال الدراسات ذات الصلة وخاصة عينة البحث بالضعف في آدائها وكفاءتها والناتجة عن قالة تخصيص الموارد المالية والواقع الذي يعيشه الفقراء في العالم بشكل عام، إذتُعد الموازنة العامة للدولة بمثابة خطة إلى شريحة الفقراء في هذه الدول.

مدروسة بحيث يكن ان تستخدم بفاعلية في تعزيز أداء الاقتصاد وبالتالي الحد من 3. مشكلة البحث انتشار الفقر ، ولكن ما تم رصده في قضية الموازنة والفتر بالنسبة للدول النامية هو قيام تنمثل مشكلة البحث بالفقرات التالية:

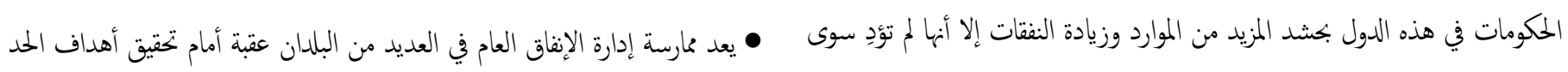

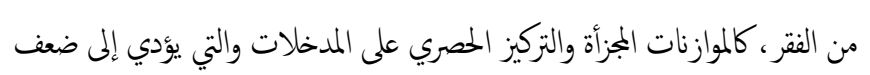

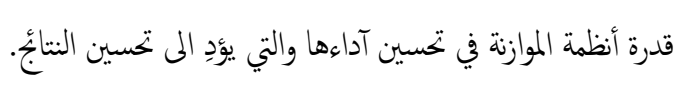

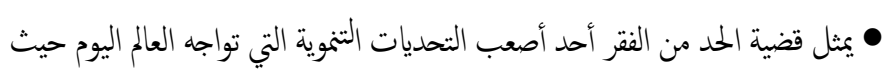

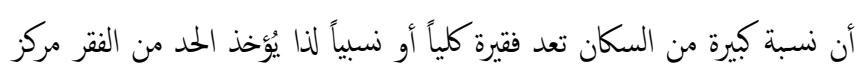

$$
\begin{aligned}
& \text { الصدارة في أجندة التنمية الوطنية والعالمية. }
\end{aligned}
$$

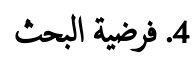

$$
\begin{aligned}
& \text { اعتمد البحث على الفرضيات الواردة في أدناه: }
\end{aligned}
$$


عملة إعداد الموازنة وإدارتها لأها تعمل كلية تسهم في توليد سوء إدارة الموارد وبالتالي فشل جميع استراتيجيات وسياسات المكومة المناهضة للفقر ، سوف يركز هذا البحث

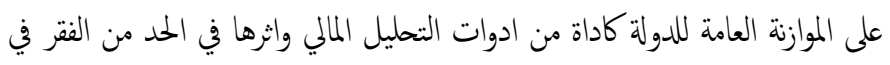
عينة الدراسة.

المجلة الككاديمية لجامعة نوروز, المجلد 8, العدد 2 (2019) ورقة بحث منتظمة نشرت في 2019/6/1

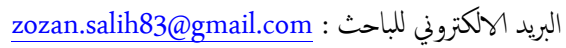

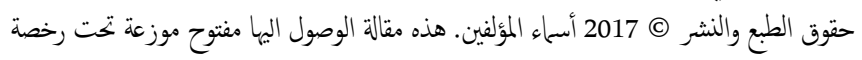

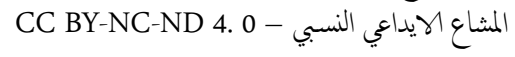


قياسه، ولغرض النعرف على ماهية الموازنة أيضاً لابد من التطرق إلى منهومها وخصائصها

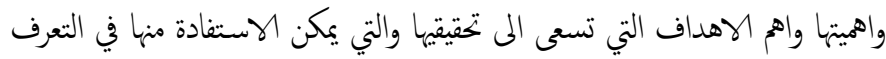

على بعض الجوانب المتعلقة بالموازنة العامة.

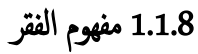

يتصف الفقر كفيره من المفاهيم الاقتصادية والاجتاعية في عدم وجود تعريف ومفهوم موحد له وصعوبة ايجاده وذلك لما لهذا المفهوم من تشابكات وابعاد مختلفة ومتنوعة منها اجتاعية واقتصادية سياسية بيئة وارتباطه المباشر بجياة الافراد ولما له من اختلافات في مفهومه بين فئات المجتع الواحد ولاختلافه من بلد لاخر ومن وقت لاخر ، ولكن محما اختلفت المفاهيم في تعريف الفقر فانها تدل على شيء واحد عند تفسيرات الجميع وهو الحرمان سواء اكلان حرمانا ماديا اومعنويا كحرية العيش بالامان والاحترام والكرامة، لذا فاذا كان عدم وجود مفهوم موحد للفتر فهو يعقد البحث فيه، ويككن اجالاً تعريف الفتر

$$
\text { بشكل عام في ثلاث اتجاهات اساسية وهي: }
$$

أ- الاتجاه الموضوعي: يبين هذا الاتجاه في تعريف الفقر تعيين مستوى معين من الدخل او الاستهلاك وذلك للتفرقة بين الفقراء وغيرهم من غير الفتراء، اذ يبين هذا الاتجاه حدا او خطا يفصل فيه بين الفقير عن غيره من غير الفقير ويبين انه من يقع فوق هذا الخط يُعد غير فقيراً اما الذي يقع على هذا الخط او دونه فهو فقير ، ويعرف هذا الحد الفاصل بخط الفقر poverty line، ويكن النعرف على مفهوم الفقر حسب هذا الاتجاه من خلال الدخل والمستوى المعيشي والإحتياجات الأساسية والقدرة الشرائية.

ب- الاتجاه الذاتي: ويقوم هذا الاتجاه بتعريف الفقر من وبجة نظر الافراد سواء كانوا فقراء أم من غير الفقراء وذلك لتأسيس مقياس للرفاهية عن مستوى المنفعة الفردية، ويختلف الفقر من حيث مفهومه بين الفقراء وغيره حيث ان الفقراء ينظرون الى الفقر بانه يعزلم عن المجتع وان الفقر تعني حياة غير آهنة مع دخل ضعيف بسبب ارتفاع نسبة البطالة بينهم ونقص فرص العمل لمم (اما بسبب مسألة المهارة والخبرة او بسبب مسالة المحسوبية والواسطة أوغيرها من الاسباب التي تؤدي المى زيادة البطالة بين الفقراء والتي تُعد هي النتيجة والسبب في نقس الوقت )، ونقص التغذية الصحيحة وحرمانهم من الوصول الى مياه الثرب، ونقص خدمات الصرف الصحي وزيادة عدد افراد الاسرة (بسبب بجلهم باساليب الوقاية
• وجود علاقة ايهابية قوية بين تخصيصات الموازنة للخدمات العامة والفقر في دول عينة

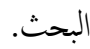

• وجود علاقة سلبية بين كل من الإففاق العسكري والدين العام مع الفقر في دول عينة البحث باعتبار أن أكثر الاحتياجات العسكرية هي من ضمن الإستيرادات، كما وأن

$$
\text { التوجه نو الدين العام يرجع إلى ضعف الآداء الملالي. }
$$

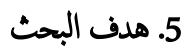

مهدف البحث لإثبات العلاقة الايهابية بين الموازنة الفاعلة للقطاع العام والحد من الفقر في دول عينة البحث، وكذلك توضيح إلى أي مدى تستطع الحكومات في هذه الدول استخدام أداة وضع الميزانية للحد من انتشار الفقر فهيا.

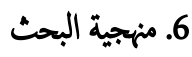

Panel Data أُعتمد البحث على المنهج التحليلي الوصفي والمنهج الكمي باستخدام لتحديد مدى استقرارية المتغيرات المالية الاساسية على الفقر في دول عينة البحث للمدة (2000 - 2015)، ومحاولة هذا البحث في وضع نموذج يكن من خلالها الربط بين الموازنة العامة السلمة ومستوى الفقر في دول عينة البحث باستخدام كل من البيانات الهائية حيث ركز البحث على الموازنة السنوية الاتحادية والإحصاءات الدولية للفقر ، غطى البحث 16 سنة (2000 إلى 2015).

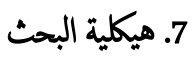
ولغرض الوصول المى هدف البحث والتحقيق من الفرضية الموضوعة للبحث فقد قسم البحث على ثلاثة مباحث أساسية تناول المبحث الاول المفاهيم الأساسية والنظرية للفقر والموازنة العامة، وتطرق المبحث الثاني المى العلاقة بين الموازنة العامة والحد من الفقر، اما المبحث الثالث فتطرق الى تحليل العلاقة القياسية بين الموازنة العامة ومؤشرات الفقر في دول العينة مع الإشارة إلى أهم الإستنتاجات والمقترحات المتعلقة بالبحث.

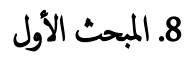
1.8 المفاهيم الأساسية للفقر والموازنة العامة تُعد ظاهرة الفقر وانتشارها في المجتمعات التحدي الككبر امام نهوضها وتطورها وقدرتها في استغلالها للموارد المتاحة فيها بالشكل الذي يستفاد منها كل افراد الجنتع وبافضل استغلال مككن، وان افضل ما يككن ان يشار اليه في موضوع الفقر هو ماهيته وكيفية 
وجود حالة من الفقر في ذلك المجتع ( البنك الدولي، 1990 ،41-42)، وبعد ما Foster, ( تعرض هذه الطريقة لقياس مؤشرات الفقر الى الانتقادات قامكل من (Greer, Thorbecke ادخال الاوزان على الفجوة النسبية للانفاق لنعكس الاهتمام برفاه افقر الفقراء، وذلك من خلال اقتراح بروفيسور امارتيا سن ( 1976) في ورقته (الفقر: مقاربة ترتيبية للقياس)، وتقوم مؤشرات قياس الفقر بتجميع المعلومات حول الفقراء الذين تم تحديدهم على وفق خط الفقر لقياس متوسط درجة الحرمان التي يعانون

$$
\text { منها(مؤشرات قياس الفقر ، بدون تاريخ،2-4)، ومن هذه المؤشرات: }
$$

i مؤشر عدد الافراد (Poverty Head Count Index (الذي يُعد مقياسا

لانتشار وتفشي الفقر باعطاهيا النسبة المؤية لعدد من الاسر أو عدد من الافراد الذين يعانون من الفقر من خلال خط الفقر اي نسبة الافراد الذين لايستطيعون تأمين احتياجاتهم الاساسية الغذائية وغير الغذائية (عثمان وعزيز، 2007، 164)، ويعتبر من أسهل المؤشرات واكترها استخداما ويككن حساب هذا المؤشر من

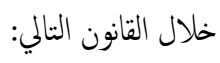

$$
\mathrm{P} 0=\mathrm{q} / \mathrm{n} \quad \alpha=0
$$

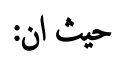

qو عدد السكان الذين يقل استهلاكهم عن خط الفقر (اي نسبة عدد الفقراء)

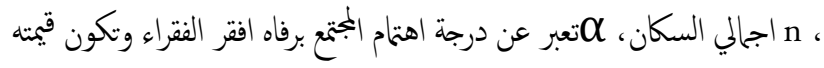
غير سالبة واكثر من الواحد، ولكن ينتقد هذا المؤشر بتجاهله لاي مدى ينحدر

$$
\text { الفقراء تحت خط الفقر ( وزارة التخطيط، بدون تاريخ،5). }
$$
ii بين اجلالي دخل او انفاق الفقراء والدخل الكلي لاولكك الفقراء لو ان كلا منهم حصل على دخل يساوي دخل خط الفقر اي المبالغ المطلوبة لاعطاء الفقراء في سبيل رفع دخولم الى خط الفقر اي حساب النكليف الكلية لوصول الفقراء الى خط الفقر ويعد مؤشر لعمق الفقر) nallari\&Griffith, 2011, 26) ويتم

$$
\text { P1=1/n حسباها على وفق القانون التالي: }
$$

او خطأ فهمه بامور الدين والشرع أوغيرها من الاسباب الاجتاعية مثل العادات والتقاليد) وكذلك قلة فرص التعليم والاستخدام السيئ للموارد وتوزيعها بين افراد الجمتع، اما غير الفقراء فقد عرفوا الفقر بانه ناتج عن الاختيارات الغير الصحية من جانب الافراد والتي تؤدي الم كل ما هو مذكور في تعريف الفقراء للفقر (محمود ويسري، 8، 2012).

ت- الاتجاه الاجتماعي: في هذا الاتجاه يُعد الفرد فقيرا إذا حصل على مساعدة اجتاعية من الدولة وحسب هذا الاتجاه يمكن قياس الفقر، وكذلك يككن تحديد اعداد الفقراء من خلال بمحوع من يجصلون على المساعدات الاجتاعية من الدولة ويُعد هذا الاتجاه تحكيميا في تعريف الفقير، لانه قد يكون الشخص غير فقير لكنه يخصل على المساعدات اجتاعية من الدولة او قد يكون فقيرا لكنه لايحصل عليها وذلك اما لجهل الفتر او عدم اتاحة المساعدات الاجتماعية او عدم وجود اوراق رسمية معه للحصول على المساعدات.

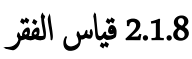

لايمكن قياس الفقر من الناحية النقدية فقط باعتباره ظاهرة معقدة ومتعددة الأبعاد والتي تنشأ من تفاعل العمليات الإقتصادية والسياسية والإجتاعية وهناك عدة مقايس مختلفة في الادبيات الدولية لقياس الفقر وذلك استنادا الى الاتجاهات المتعلقة بتعريف

$$
\text { الفقر في إطار الاتجاه الموضوعي ومن هذه المقايس: }
$$

أ- قياس الفقر عن طريق مؤشر الدخل او الاستهلاك: وذلك عن طريق الحرمان الناتج عن نتص القدرة على شراء السلع والخدمات والتي يكن الحصول عليها من بحوث الدخل والاستهلاك والانقاق، اذ يعد تقرير البنك الدولي في عام 1990 عن الفقر خطوة جيدة خو قياس الفقر بمؤشر الدخل أو الاستهلاك أو المستوى المعيشي حسب تعريف البنك الدولي للفقر ، وتبدأ هذه المنهجية بالتفرقة أولاً بين الفقر وعدم المساواة حيث ان الاول يُعبر عن المستوى المطلق لمستوى معيشة جزء من السكان وهم الفقراء في حين ان الثاني يعبر عن المستوى المطلق النسبي للمعيشة في الجمتمع ككل، وهناك حالتان لعدم المساواة والتي يمكن من خلالها بيان الحلالة التي يعيش فيها الجنتمع، اذ انه في حالة الحد الاقصى من عدم المساواة تعني ان هناك شخص واحد يتحكم بكل شيء والفقر الموجود في المجنع هو فقر شديد جدا وانه متوفر بدرجة كيرة إذ أن الجميع فقراء، أما في حالة الحد الادنى من عدم المساواة تعني ان الجميع في المجتع متساويين، والفقر الموجود هو صفر اي عدم 


$$
\mathrm{Z}=\mathrm{Zf}+\mathrm{Znf}
$$

حيث ان : Z = (متوسط الحاجة للسعرات * كلة السعرة الواحدة) + الانفاق فير الغذائي للاسر او الافراد، Zf = خط الفقر الغذائي ويثل عدم استيفاء الفرد السعرات الحرارية اللازمة له محسوبة بعدد السعرات المستهاكة * كلفة السرة

الواحدة لكل مادة غذائية.

1.3.8 - ياس الفقر من مفهوم القدرة

حيث قام برنامج الام المتحدة الانمائي بتقديم مفهوم فقر القدرة وذلك لان مقايس الفقر القائمة على اساس الدخل او الانقاق وتُعد مقايس جزئية ولايؤخذ بنظر الاعتبار الخدمات والسلع الضرورية لمستوى المعيشة مثل الخدمات الصحية والتعليمية والبيئة Amartya sen النظيفة وبذلك لايقاس نوعية الحياة، وان هذا المقياس قائم على آراء في قياس نوعية الحياة على اساس القدرات والتي تشير الاخيرة الى بموعة من الوظائف التي يكن للناس القيام بها وتحدد مالديهم من خيارات للوصول الى عدد من الوظائف وذلك لانه كلما زادت القدرة زادت مشاركة الناس في عملية التنمية، ويقاس الفقر وفقا لهذا المفهوم بمدى الحرمان من ثلاث عناصر اساسية للحياة البشرية وهي العمر الطويل اذ يمثله في الرق القياسي للفقر البشري النسبة المئوية للاشخاص الذين يتوقع وفاتهم قبل سن الاربعين، والمعرفة والتي تقاس النسبة المئوية لعدم معرفة القراءة والكتابة بين البالغين، واخيرا مستوى المعيشة اللائق والتي هي مركة في الاصل من ثلاث متغيرات اساسية وهي النسبة المئوية للاشخاص الذين لاتتوفر لمم فرص الحصول على الخدمات الصحية والمياه المأمونة واخيرا النسبة المئوية للاطفال دون سن الخامسة والذين يعانون من سوء النغذية، ويُعد هذا المقياس هو الاوسع من بين المقييس الاخرى والمتعلقة بالدخل والانفاق، ولكن هذا المقياس يتطلب قاعدة بيانات جيدة عن الظروف الصحية والتعلمية والغذائية للفقراء في المجتمع وانها صعبة التطبيق في الدول النامية لعدم توافر

قاعدة بيانات يكن الوعتاد عليها.

3.1.8 صعوبات قياس الفقر (الفارس، 2001، 24-26)

كما ان هناك صعوبة في تعريف الفقر تعريفاً موحداً كذلك يوجد بعض الصعوبات التي لايمكن اخفاءها عند تقدير خط الفقر ومن الواضح ان تقديرات الفقر هي تقديرات تتسم بعدم الدقة في بعض الاحيان ومن الصعوبة بكلن تقديرها تقديراً واضحا وصريحا وذلك بسبب المشاكل المتعلقة بقياس الفقر في تقدير الاحتياجات الاساسية من السلع الغذائية وتربمتها المى ارقام وبالمقابل تقدير حاجة الجسم من السعرات الحرارية ومن الوضح ان

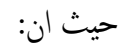

n = اجالي عدد السكان، Z= خط الفقر المستخدم، Yj = دخل او انفاق الفرد، Pتوسط دخل الفقراء، J = الافراد تحت خط الفقر، I = متوسط جفوة YP




باعطاء الوزن الاكبر للاسر التي توجد عند قاع مستوى توزيع الدخل وايضا يعتبر مؤشر يقيس درجة عدم المساواة في التوزيع تحت خط الفقر من خلال:

$$
\mathrm{P} 2=1 / \mathrm{n}=\sum_{j=1}^{q}[(z-y j) / z] \quad \alpha=2
$$

P2 شدة الفقر ، = = اجالي السكان، z = خط الفقر المستخدم، Y د دخل او انفاق الفرد، ز = الافراد تحت خط الفقر ، ويكن قياسه من خلال فجوات الفقر ونسبة الفقر عن طريق الصيغة التالية: $\mathrm{P} 2=(\mathrm{pg})^{2} / \mathrm{H}+(\mathrm{pg} \cdot \mathrm{H})^{2} / \mathrm{H} .\left(\mathrm{cv}^{2}\right) \mathrm{p}$

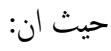

P2 = شدة الفقر ، Pg = جوة الفقر ، H = نسبة الفقر ( نسبة سكان الفقراء الى جموع السكان)، (cv²)p = مربع تباين الاستهلاك بين الفقراء، ويقوم هذا المؤشر بتوضيح مدى حدة الفقر بترتيبه لتوزيعات الدخل ولكن ينتقد لصعوبة تفنيره. iv مؤشر سن(sen) الفتر: وحسب مؤشر سن للفقر فان الصيغة التالية يقيس الفقر (Ravallion, 1992,39): $\mathrm{P}=\mathrm{H} \cdot \mathrm{G}^{*}$

حيث ان: P = درجة الفقر ، H= نسبة الفقر ، G = معامل جيني المعدل وياخذ

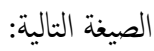

$$
\mathrm{G}^{*}=\mathrm{M}+(1+\mathrm{M})-\mathrm{G}
$$

حيث ان : G = معامل جيني، M = نسبة جفوة الدخل. ويكن الحصول على الحد الادنى الذي على اساسه يكن تصنيف السكان اسرا وافرادا الى فقراء وغير الفقراء( الجهاز المركزي للاحصاء، 2007، 6) باستخدام

المعادلة التالية: - مالية 
والدخل وغيرها من الانشطة المالية وغير المالية اي ان الموازنة هي وسيلة الحصول على Joshua and Ahmed, 2013, (المساءلة والتحكي في استخدام المال لميع الانشطة

.$(40-41$

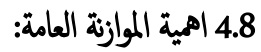

تاتي اهمية الموازنة العامة لكونها تثثل آداة فاعلة في تحقيق اهداف الدولة ووسيلة مؤثرة في توجيه المجتع من النواحي الاقتصادية والاجتاعية والسياسية ومن خلالها يتمن الحكومة من تحقيق سياساتها العامة، وبشكل عام فإن لموازنة العامة اهمية اقتصادية ومالية وسياسية واجتاعية، ويكن التطرق المى اهيته من تلك الجوانب وبالشكل التالي: أ- الامية الاقتصادية: تأتي هذه الاهمية للموازنة العامة من خلال السياسات الاقتصادية والفكر السائد للدولة حيث إن الاقتصاد الحر يكون فيه دور الدولة محدودا وبحاية الموارد الموجودة في المجتمع في حين تزداد اهيتها بزيادة تدخل الدولة في الحياة الاقتصادي من خلال توجيه السياسات الاقتصادية والتحكم بنفقاتها وايراداتها من خلال الموازنة العامة(العلي وكداوي،1989، 276).
تقدير هذه الحاجات غير متفق عليها اذ تخضع لبعض التأثيرات ومن بعض العوامل المتصلة بالاسر من حيث تركيها وان تأثير كمية هذه الحاجات مرتبطة بمقدار الجها الذي يبذله افراد الاسرة وطبيعة العمل الذي يقومون به وان هذه التقديرات غير ثابتة وتتغير من سنة لاخرى، وذلك حسب منهجية التقدير المتبعة واختلاف الاسعار او قد تكون هنالك بدائل اخرى للسلع الغذائية يكن من خلالها تلبية حاجات الجسم من البروتينات التي تحتابحا او قد تكون هنالك اهداف اخرى غير الاشباع والحصول على البروتينات من استهلاك الافراد للمواد الغذائية والتي يصعب قياسها مثل الاذواق والاهتمات وغيرها من العوامل المتعلقة بشخصية الافراد وافكارهم والتي من المستحيل قياسها.

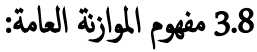

لا يوجد تعريف محدد لمفهوم الموازنة العامة بسبب اختلاف الزاوية التي يُنظر بها الى الموازنة من قبل الكناب والباحثين كما ان مفهومها يختلف بين الوحدات الحكومية عن غير الحكومية وبين الوحدات الحكومية المركزية عن تلك الوحدات الحكومية المستقلة، كما إن اجراءات وضوابط اقرار الموازنة وتعديلها وتنفيذها للحكومة المركزية متشددة اكتر عن تلك الحكومة غير المركزية او التي تعتمد على الاستقلالية بين وحداتها وعلى الرغز ب-الاهمية المالية: من الواضح ان الموازنة العامة تكشف الوضع الملالي للدولة من خلال قدرتها في التميز بين الانواع الخختلفة للموارد المتوفرة في الدولة خلال السنة القادمة ضرائب ورسوم ودخل المشاريع الاقتصادية للدولة من الصناعة والزراعة والتجارة وغيرها من الموارد المالية كايرادات للمولة، وكذلك في مجالات انفاقها من خلال القطاعات والوزارات والدوائر وغيرها من المؤسسات الحكومية التي تتناج الى نقات والتي تساعد الدولة في النعرف على وضعها المالي من فائض او جزز في موازنتها للسنة المالية القادمة. ت- الامية السياسية: إن اقرار الموازنة العامة يعد امراً حماً في تجديد الثقة بالحكومة وببرنامجها الذي ستعمل على تنفيذها، حيث إن حق اقرار الموازنة العامة هو حصر وحكر بالسلطة التشريعية من خلال اعطاهيا سلطة وحق في مناقشة جدول الحكومة وبرناججها المالي واحداث النغيرات والتعديلات اللازمة عليها ومن ثم اعطاء السلطة التنفيذية الاذن بتنفيذ مشروع الموازنة للحكومة. ث- الومية الاجتاعية: تُعد الموازنة العامة للدولة من أهم أدوات حاية المجتع من التفاوت الطبقي وذلك من خلال تاثيرها في اعادة توزيع الدخل بين طبقات المجتع، وذلك عن طريق فرض الضرائب التصاعدية وخاصة الضرائب المباشرة واستخدام حصيلة تلك الضرائب في تمويل المشروعات العامة بحيث يستفيد منها الطبقات الفقيرة في المجتع، من ذلك فان الموازنة تعد اساس يعتمد عليه العمل المالي للحكومة بشكل عام ومتطلب تشريعي اساسي حيث تُعد خطة مالية سنوية تتضمن تقديراً للنفقات والايرادات الحكومية وهي المرآة التي تعكس الانشطة الاقتصادية والاجتاعية للدولة وتعبرعن اهداف الدولة وبرامجها وسياساتها في كيفية استغلالها لمواردها المالية وطاقتها البشرية وكيفية توزيعها بين اوجه الانقاق التي تحقق من خلالها هذه الاهداف والبرامج والسياسات الخاصة بها، كما ان لها خاصية اللجوء المى عملية المفاضلة بين البرامج والبدائل الموجودة طبقا لامكانياتها، وبذلك تُعد من اهم الوثائق التي تبين السياسات العامة للدولة والوسيلة التي يتم استخداما من قبل السلطة التشريعية في الاستدلال على كفاءة اجززة الحكومة التشريعية والتنفيذية والرقابية من خلال مدخلات ومخرجات الموازنة في تحقيق التنمية الاقتصادية والاجتاعية، و يكن تعريف الموازنة العامة أيضاً على انها بموعة من الاهداف والبرامج المعبر عنها بالارقام والتي ترغب السلطة السياسية المتمثلة بتنفذها من خلال وحدات الدولة المختلفة وباقل التكليف خلال فتزة مستقبلية معبرا عنها بحجم كلة كل هدف او برنامج مع بيان مصادر التمويل التي ستحصل عليها الوحدات خلال نفس الفترة (سلوم والمهايني،2007، 95-97)، وتعرف الموازنة بانها عملية وضع معيار الاداء على الانشطة المقبلة من اجل ممارسة السيطرة على النكاليف والايرادات 
• وبما أن الموازنة العامة جزء من خطة قومية عادة تكون متوسطة الاجل او طويلة الاجل اي يكون مرتبط بخطة قومية واجب التنفيذ والتي تؤثر وتبين بشكل او آخر

$$
\text { امكانيات الدولة ودقة آدائها. }
$$

•وتُعد الموازنة العامة خطة مالية في جمبع الوحدات الحكومية والتي تشتمل على التقديرات المالية لمدة سنة مالية قادمة وتقديراتها العينية والتي تعنى بتشكلات

الوظيفية اي اعداد وفئات الوظيفية كما ان لها امكانية التنبؤ للمدى الطويل.

• وتتميز باقامة روابط واسعة بين الاهداف وتنظيمها و تعزيز التواصل بين المقيمين بتنفيذ

الخطة.

• وتتزكز الموازنة على ننائج القرارات للسنوات السابقة وامكانية الاستفادة منها في السنوات اللاحقة بقيم مالية في شكلها الهائي اي ترجمة كافة البيانات والانشطة الى الارقام والتعبير عنها بوحدات نقدية.

• ومن خصائصها انها يكن ان تكون اداة رقابة فاعاة في التاكد من سلامة الخطة في موضع التنفيذ الى جانب كنها اداة لتقييم عملية الاداء في كيفية تطبيق وتنفيذ المشاريع والبرامج الاقتصادية والاجتاعية الموجودة في الخطة السنوية، اذ ان عملية تقييم الاداء هي عملية المقارنة بين الانجازات ( الاداء الفعلي) والموازنة المخططة ( الاداء الخخطط) اي تعبر عن الانجازات التي تحققت ومدى انعكاسها للبرامج والمشاريع

$$
\text { المقترحة في الموازنة. - مان. }
$$

• وتعد الموازنة بمثابة الخطة لتنسيق والتوجيه في كيفية سير العمل نو تحقيق الاهداف الموضوعة في الموازنة وضمن امكاناتها وتقديراتها المالية والمادية الى جانب كنها تعتبر خطة شاملة لمجيع اوجه الانشطة الاقتصادية والاجتاعية..

2.8 1.2.8 الإطار النظري للعلاقة بين الموازنة العامة والحد من الفقر أ- العلاقة بين الموازنة العامة والحد من الفقر: عالميا تتجه عملية الموازنة تدرييا نحو اولويات الحكومة واصبحت العمليات اللامركزية تسيطر عليها من خلال الاهتمام بالديمقاطية في اعداد وتنفيذ الموازنات الحكومية، ومن خلال المشاركة الاجتاعية وبذلك تخصيص الموارد والانفاق العام في الموازنة العامة للدول تأخذ اشكلا جديدة لغرض القيام باستراتيجيات الحد من الفقر وتؤثز متغيرات الموازنة على الفقر من عدة جحات، كما ان الموازنة تعكس توجحات السياسات المالية لدولة في تركيزها على القضايا
وكذلك قياما بدع الدولة لسلع استهلاكية ضرورية، فضلاً عن دع التعليم، والصحة

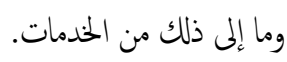

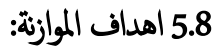

لماكانت الموازنة هي خطط التعامل مع كيفية استخدام الموارد المحددة خلال فترة زمنية محددة ومعينة مع هدف مشترك في جميع الدول وهو السيطرة على الموارد المتاحة من خلال السياسات القائمة (Abrahams, 2012, 19)، بذلك يكن تحديد اهم اهداف

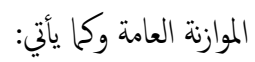
• تحتيق الرفاه الاجتاعي والاقتصادي من خلال تحقيق التنمية المستدامة ، حيث أن أهداف الموازنة اصبحت طويلة المدى كما وان خطط الموازنة في كل سنة تعتبر متممة

$$
\text { للسنوات السابقة لغرض تحقيق هدف التنمية المستدامة. }
$$

ا القيام بتشجيع الانشطة الانتاجية والحد من الانشطة غير الانتاجية من خلال ضبط الانفاق بتوجيها اكثر نخو النفقات الاستثمرية والتقليل من النفقات الإستهلاكية. • القيام برفع انتاجية العمل الاجتاعي والحد من البطالة من خلال ايياد الوظائن. التشغيلية وتفعيل القطاع الخاص وتشجيعه وزيادة مساهمته في الناتج المحلي الاجلالي وذلك لتقليل العبء على الحكومة من النفقات التشغيلية. • زيادة الدخل القوي من خلال تشجيع الناتج المحلي والانشطة والمشاريع الصغيرة في

• دع الميزان التجاري من خلال تشجيع الصادرات والحد من الإيرادات المستهلكة. 6.8 خصائص الموازنة العامة

تحتوي الموازنة العامة على عدة ميزات وخصائص اساسية هي (Esser, 1999, 3): • من اهم خصائص الموازنة العامة والتي لاتشارك اية موازنات او ميزانيات اخرى في هذه الخاصية هو اعتمادها من الجانب القانوني واجبة التنفيذ بعد اعدادها واعتمهها من قبل السلطة التشريعية ومجلس الوزراء ولايمكن اجراء اي تعديل عليها بعد اعتمادها واقرارها من قبل السلطة التشريعية إلا بموجب القانون والذي يجب أن يأخذ

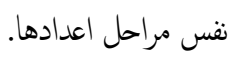


يؤثر الاستثمار على النمو والانتاج الكلي المجتع، فضلاً عن تأثيرها على مستوى الاقتصاد الجزئي وعلى المستوى القطاعي لدخل الاسرة وخاصة الفقيرة فيها وتوزيع الدخل، حيث ان الدلائل على وجود تأثير للاستثمارات على الفقر او وجود علاقة بين الاستثمرات والفقر يكاد يكون قاطعا، كما ان قرار القيام بالاستثمارات العامة يجب ان يكون قائما على اساس البنية الاقتصادية للبلد ورأس المال الموجود فيها، حيث ان تأثير الاستثمارات العامة على الفقر يكون من خلال تأثيرها على مجالات اخرى مثل النقل والاتصالات والبحوث والتنمية الزراعية وغيرها من المجالات التي يمكن الاستعانة بها من خلال الاستثمرات العامة في القضاء على الفقر ، وبذلك يمكن تحديد صافي الاستثفرات العامة على انها الانفاق العام الذي يضيف الى لى رأس المال المادي والاوراق المالية، والذي يشتمل على بناء الطرق والموانئ والمدارس والمستشفيات والمى آخره من البنى التحتية والذي يتوافق مع تعريفها في بيانات الحسابات القومية والتي تعرف بانها النفات الاستثمرية. ثانيا: النمو الاقتصادي Economic Growth : منذ دخول العالم في العصر الجديد من التطور الاقتصادي ولحد الان تسعى كل الجهود الدولية الى هدف واحد وهو الحد من انتشار ظاهرة الفقر او القضاء عليه، ومن الشائع دوليا ومحليا وعلى مستوى ثقافة الافراد في ان النمو الاقتصادي هو ماتتناج اليه الدول لتحقيق هدف القضاء على الفقر او الحد منه، ولكن ليس واضحا تماماك هو معدل النمو التي تتناج اليه لهذا الغرض، ومدى التمويل الخارجي المطلوب للوصول والحفاظ على اعلى نمو ممكن ولكن هذا لايعني في ان النمو وحده يكني لهذا الغرض، ولكن يجب ان يتبع عملية النمو بعدد من السياسات الحكومة لهذا الغرض مع ان هذه السياسات هي الاخرى غير واضحة في كيفة مساهمتا بغعالية مع سياسة النمو في القضاء عليه (Gottschalk, 2000,2)، ويُعد النمو الاقتصادي من اقوى العوامل ". المؤدية الى الحد من هذه الظاهرة وتحسين نوعية الحياة في البلدان النامية من حيث قيامحا بتوليد الازدهار الاقتصادي وزيادة الفرص المتاحة للعمل وان نجاح استراتيجية الحد منه يتوقف على التدابير الرامية الى تعزيز النمو الاقتصادي المستدام ويتثل في التحدي في اخذ السياسة التي تجمع بين تعزيز السياسات المؤدية للمو والسياسات التي تسمح للفتراء في المشاركة الكاملة في الفرص المتاحة، اي المساهمة الفاعلة للفقراء في عملية النمو ومشاركنهم المجتع في الحصول على نتائجها مثل تغيير سياسات العمل على نخو افضل في اسواق العمل وازالة الفوارق او
الاقتصادية والاجتاعية المختلفة بطرق مباشرة وغير مباثرة في الحد من الفقر من خلال القنوات التوزيعية للدخل اما باستخدام سياسات الانفاق العام او باستخدام الوسائل الضريبية كما ان للسياسات المالية اثر على هيكل الموازنة العامة (والذي يقصد به التوزيع النسبي لاجلالي الانفاق على بنود الانفاق) وليس فقط على مستوى الانفاق الحكوي كما يمكن ملاحظة ان معظم البلدان النامية تتوجه نحو تزايد الانفاق العسكري على حساب نصيب الانفاق الحكومي على القطاعات الحكومية (مثل التعليم والصحة والتغذية) الموجحة نحو القضايا الاجتاعية مثل الرعاية الاجتماعية ( النجفي، 2007، 13-13)، وتهدف نهج او استراتيجية الحد من الفقر الى تعزيز المساءلة عن طريق المشاركة المحلية من اصحاب المصلحة في صياغة واضحة للاهداف الانمائية، كما ان المؤسسات التعليمة والتدريبية يتضمن المتابعة وتقييم من خلال التقارير السنوية، ومنذ ان قامت الدول باستراتيجية الحد من الفقر دعت الجهات المسؤولة عن وضع السياسات الم تشجيع ادخال عدد من الطرق التي تهدف الى تحسين كيفية استخدام الخطط في الموازنة العامة لغرض الحد من الفقر ، والتي تضمنت: - استراتيجية اولويات الانفاق لصالح الفقراء. - ادخال اوجه الاتفاق في المدى المتوسط. - القيام بتوجيه البرامج والخطط في الموازنة الى استهداف الفقراء. وتعكس هذه الاصلاحات في مراحلها المختلفة وفي ختلف الدول مستوى التنمية العامة في النظم المالية للدولة، كما انه تؤخذ في نظر الاعتبار مصاح بمحوعة واسعة من افراد المجتع وتمكت من خلالها توليد حوافز قوية في تغيير السلوكيات باتجاه التنفيذ (worldbank,2007,2-5)، ويكن النعرف على أهم بنود الموازنة المتعلقة والمؤثرة بشكل مباشر أو غير مبانشر بالحد من الفقر حيث أنه ومنذ عام 1950 حدثت تغيرات جوهرية في تتصيص المعايير الوطنية والاقليمة والموارد المحلية العامة وفي نجج الموازنة التي تقوم الحكومة بتنفيذها، وكذلك البحث عن مصادر جديدة من اجل تخصيص التمويل للتنمية واستراتيجيات الحد من الفقر ، لذا سوف يتم التطرق الى اهم البنود التي تؤثر بصورة مباشرة وغير مباشرة على استراتيجيات الحد من الفقر من خلال بنود الموازنة

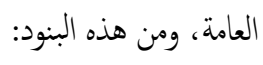
اولا: الاستثمار Investment: هنالك عدة قنوات يمكن من خلالها أن يؤثر الاستثمر بشكل عام على جوانب الاقتصاد، حيث على المستوى الاقتصاد الكلي يمن ان 
حول السكان والمو والفتر ، ولكن لايوجد دليل لحد الان حول العلاقة السبية بين كل من الازدهار الاقتصادي والخناض الخصوبة ولكن يوجد هنالك ارتباط وعلاقة وثيقة بين نمو الدخل القوي والخفاض معدلات المواليد، وبين دخل الاسرة والخصوبة، ولكن معظم الاقتصاديين والديوغرافيين متفقين على ان المكونات الاساسية في تحسين مستويات المعيشة من التصنيع الحضري وزيادة فرص العالة قد تؤدي الى خسين مستويات الثعليم والصحة الافضل، وكل هذه الامور ادت الى تغير نظرة الابوين لتكليف وفوائد الاطفال مما يؤدي بدوره في اغلب الاحيان المى خضض الخصوبة ولكن هذه العلاقة هي ليست مطلةة بين البلدان فيا يتعلق بتوقيت هذه التغيرات وسرعتها مع الاجلحع على ان هنالك علاقة سبية National Research ( بين التحسن في مستويات المعيشة وانخفاض الخصوبة (Council, 1986 كما وان من اسباب ان تدني الخصوبة يؤدي الى التحسن في المستوى المعيشي لان معدلات النمو الاقتصادي تصبح أعلى من معدلات النمو

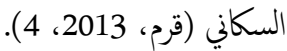
خامسا: الثقل Transport: يكاول الجمتع الدولي وضع اهداف في تخنيض مستوى الفقر الموجود منذ أكثز من قرن وبشتى الطرق والوسائل، وأحد هذه الطرق هو الوصول الى إيجاد العلاقة بين قضايا النقل والفقر من بهة والحد منه من بهة أخرى، مثل تأثير النقل بكل أنواعه على التعليم وعلى الصحة وعلى كيفية توليد


من المدن والأرياف ولكن الآثار الدقيقة والمترتبة على وجود خدمات النقل وكيفية تأثيرها على الإخناض والتقليل من القتر الى جانب زيادة المو قد يختلف مع مرور الوقت والمكان وبين ختناف قطاعات السكان، كما ان معظم الاستثارات في البنية التحتية مبنية على الاعتقاد بأنها ستؤدي حتا المى الحد من النقر وتوليد الدخل، إلا أن الجدوى من وجود قطاع النقل يختلف بإختلاف التقدم وتطور الدول، ولكن يوجد هنالك بعض من الجملات الرئيسية لسياسات النقل والتي يمكن ان تساءد الفقراء كتوفير النقل الكلفي إلى أماكن العمل وذلك بسبب اهية تكلفة وتوافر النقل الى العمل بالنسبة للققراء وخاصة بالنسبة للذين يعيشون في المناطق الحضرية والتي تعتبرعامل ومحد رئيس لقدرتهم على المشاركة في أسواق العمل وإزالة العوائق أمام النقل غير الآلي كما أوصى البنك الدولي عام 1996 بالتعامل

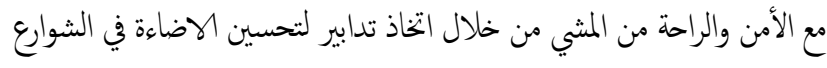

عدم المساواة بين الجنسين والمنو في المستقبل يجب ان يقوم على اساس العولمة التي تقدم الكثير من الفرص الجديدة الى جانب التحدي الذي يفرضه .(Ravallion and chen,1997,357)

ثالثا: الكفاق العام Public Expenditures : يعرف الانفاق الحكوي على انها نققات لتمويل الانشطة الحكومية التي تهدف الى الرعاية الاجتاعية عن طريق استخدام بضض الموارد الانتاجية الى جانب الاموال(Birowo, 2011,18)، وبنلك تلعب الانفاق الحكوي دوراً هماً في الحد من الفقر فطقا للنجج الكيني فان الانفاق العام يؤدي الى زيادة الطلب الكلي والذي يؤدي الى تحنيز النمو الاقتصادي والتوظيف، ويؤز الانفاق الحكوي على الفقر بشكل مباشر من خلال تلتي الفقراء الفوائد من نققات المكومة على برامج التوظيف والرعاية، كما انها تؤثز بشكل غير مباشر من خلال الاستثمارات الحكومية في البنية الاساسية للريف ودم البحوث الزراعية والصحة والتعليم لسكان الريف وتخيز لمناطق النمو في الزراعة وغير الزراعة ممائدي المى زيادة العالة وكسب فرص الدخل لهم الى جانب

رخص المواد الغذائية للسكان وبالتالي زيادة النمو الاقتصادي ( Dahmardeh \& Tabar, 2013, 252 )، كما ان الانفاق الحكوي بهدف ويؤر ايجابيا على النمو الاتصادي والحد منه كنتيجة لتحسين توفير الخدمات الاجتاعية من المنافع العامة والانفاق على الزراعة وصولاً الى البنية التحتية، وان تأثير الانفاق الحكوي بشكل غير مباشر على الحد من الفقر هو اكثر اهية لانها تعمل من خلال مستوى


معدل معرفة القراءة والكتابة بين افراد الجمتع ومعدل وفيات الرضع الى جانب كيفية

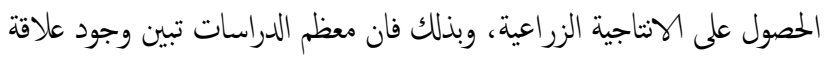
ايجابية بين الانفاق الحكوي والنمو الاقتصادي في حين لايجب ان نغفل إن الزيادة

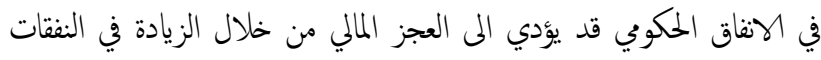
الجارية وغير المتنجة وعدم قدرة الاقتصاد في الحصول على الضرائب وخلق ضرائب

جديدة في الاقتصاد (Mehmood and Sadiq, 2010, 29-35). رابعا: نسبة السكان populations : منذ زمن ولحد الان يجري النقاش بين علاء الاتتصاد والاجتلع حول فيا اذا كان ارتفاع الحصوبة والمو السكاني السيع يؤز ايجابا على الاقتصاد ام يؤزر سلبا عليا وكذلك بالعكس في كيفية تأثير النمو الاقتصادي على السكان، اي ان النقاشات تحدث على المستويين الكلي والجزئي 
الطوارئ والتي تكون محددة على نخو أضيق ولاسيا تلك المتعلقة بالصحة والضعف

الناتج عن نتص الأغذية أو المعاملة التعسفية) (UNDP,2013, 6). ثامنا: السكن: إن معظم التعاريف حول الفقر والحرمان المادي هو متعلق تماما بظروف السكن، أي أنه يساهم مساهمة كبيرة في الظروف المعيشية المادية، وفي ظل اقتصاد السوق فإن الفقر والثروة الضعيفة يحول دون الوصول إلى العديد من خيارات الإسكان ويجعل من الصعب الحفاظ علها، كما إن استحقاقات السكن ودعز الأشخاص المشردين هو بمثابة المخزن المؤقت للفقراء. ب- النظريات المتعلقة بيان العلاقة بين الموازنة العامة والحد من الفقر: إن تحسين ظروف معيشة المواطنين بما في ذلك الحد من الفقر لا يمكن التخلي عنه لأنه يشكل أحد أكبر احتياجات حكومات العديد من البلدان اليوم سواء متقدمة النمو أوالنامية هذا يضع الطلب على الكفاءة على خضصات الموازنة حيث أن تخصيص الموازنة بشكل فعال أو مجدي لقطاعات الاقتصاد هو الذي يكن أن يقرب الحكومة من الشعب وبالنالي الحد من الفقر كما وتعني الكفاوة التخصيصية لعملية الموازنة أن موارد الحكومة هي قناة تقود إلى مناطق أو قطاعات من الاقتصاد تسهل تحقيق احتياجات الحكومة من الاقتصاد الكلي بما يتاشى مع أولويات المواطنين وفي ضوء العلاقة بين الموازنة العامة وسياسات الحد من الفقر يوجد ثلاث نظريات

تبين طبيعة العلاقة بينها (Ben- Caled, 2015, 107-114): أولاً: نظرية الاختيار العام Public Choice Theory (PCT) : تم تطوير هذه النظرية من قبل خبراء الاقتصاد العام لشرح سلوك صانعي القرار بما في ذلك هُ هُ الحكومة أي أنها تتعلق بالدراسة الاقتصادية لعملية صنع القرار غير السوقية، ولا سيا تطبيق التحليلات الاقتصادية على صنع السياسة العامة، ويقوم الافتراض الأساسي لهذه النظرية على أن صانعي القرار (السياسيين أو البيروقراطيين) عقلانيون كهمون بذاته، بمعنى تحسين خياراتهم واستخدام المعلومات المتاحة لمصالحهم وهذا هو السبب في معارضة الإقتصادين لهذه التسمية وذلك لأن الاختيارات الوحيدة التي يعترف بها هي في الأساس ووفقًا للنظرية، فإن صناع القرار - سواءكنوا من الناخبين أو السياسيين أو المشرعين أو المديرين التنفيدين أو البيروقراطيين أو الحكومة - يسعون لمصلحته الشخصية في إطار المصلحة العامة، أكثر من ذلك أشار داونز (1957) في (Fozzard (2001 إلى أن اهتمام السياسي هو تعظيم السلطة السياسية
والأرصفة وغيرها من مرافق المشاة، الم جانب أن يكون توجه سياسة الحكومة مباشرة ضد احتياجات الفقراء الى النقل في أماكن عملهم والتي لو وفرت هذه الأسباب في سهولة إنتقال العال الفقراء من وإلى أماكن عملهم لأدى ولو بشكل بسيط إلى الحد أو التقليل من ظاهرة الفقر ، والقيام بإعطاء القطاع غير الرسمي حرية تشغيل خدمات النقل والتي ترجع أهميته في إمكانيته بتوفير خدمات للنقل والتي يتحقق أسعاره من قبل الدولة (World Bank,,1996)، كما يجب إتخاذ تدابير اللازمة لتجنب الآثار الاجتاعية السلبية لبعض المشاريع البنية التحتية الكبيرة على الجمتمعات المحلية والتعويض عنها ) Booth, Hanmer \& Lovell, .(2000, 83-89 سادسا: الخصخصة Privatization: يقصد به نقل ملكية ملوكة للحكومة في المشاريع العامة للمساهين في القطاع الخاص، أي هو نقل ملكية الأعمال الحكومية إلى الأفراد والمنظمات الخاصة، كما يعد أحد الابتكارات الثورية في السياسات الاقتصادية لكل من البلدان النامية والمتقدمة، إذ إن الهدف النهائي لأي حكومة ذات مصداقية ومشروعة هو ضمان التحسين المستمر في مستوى معيشة المواطنين، كما إن سياسة الخصخصة الاقتصادية هي نتاج الإصلاحات الليبرالية الجديدة التي أصبحت شائعة من خلال البنك الدولي وصندوق النقد الدولي كما أنها بدأت لأول مرة في شيلي تحت الحكم العسكري عام 1974 ومن ثخ اعتمد عليها في بريطانيا بين عاي 1986 و1987 كجزء أساسي للتحول في السياسة الاقتصادية (ANAYO, 2013,11) .

سابعا: الضمان (الماية) الاجتاعية Social security: يعد الضمان ( المماية ) الاجتاعية إحدى الطرق للحد من آثار الفقر والتخفيف من حدة تعرض الناس لها إذ أن مستويات دخل الفرد وعدم المساواة الناتجة عن أداء اقتصاد السوق يترك دائما بعض الناس في حالة الفقر وكذلك يعرضهم لحالات الطوارئ وبذلك رن تهدف سياسات المحاية الاجتاعية الى التخفيف من حدة هذه المشاكل وذلك للمساهمة في تحقيق النمو لصاح الفقراء، إذ أنها تثفاعل من خلال طريقتين للحد من الفقر ، الأول: إن من المشاكل الأساسية هي الدخل المنخفض لذلك يتم توجيه المساعدة الى ارتفاع الدخل وتشمل هذه الفئة برامج الرعاية التي توفرالدخل للمستفيدين إما بشكل نقدي أو عيني، والثاني: هو البديل الموجه إلى حالات 
الفقر في هذه النظرية ويرجع ذلك إلى أن خصصات الموازنة من المتوقع أن تقدم

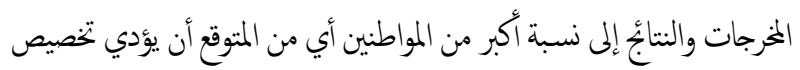
الزراعة إلى زيادة إنتاج الغذاء في البلاد وبالتالي الحد من الجوع وكذلك أن يؤدي الإنفاق على التعليم إلى خضض الأمية وأن يؤدي الإنفاق على الصحة إلى خضض معدل وفيات الأطفال والرضع في حين يتوق الإنفاق على النقل ثتقليل عدد حوادث الطرق النامة عن الطرق السيئة وأن يكون للآثار المشتركة

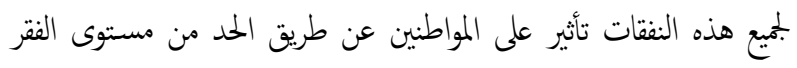
وحدوثه. كالثا: نظرية النظم The Systems Theory كان ينظر إلى النظام على أنه بموعة من الأجزاء المتزابطة والتي تعمل من خلال الثفاعلات ككل كلى نظام إما جزء


(GST) ولهذه الغاية يككن تطبيق منهوم النظام العام على دراسة وإدارة المنظات سواء كانت خاصة أو عامة ويكن النظر إلى المنظمة على أنها ظظام يتكون من أنظمة فرعية ختنافة هي: نظام الإنتاج ونظام التسويق وظظام الحاسبة وما إلى ذلك، ويكن تقسيم هذه الأنظمة الفرعية نسها إلى نظم فرعية أصغر وأصغر كما وتعد

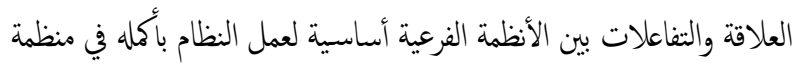
تشتمل عمليات الربط هذه على التواصل والثفاعل الاجتاعي واتخاذ القرارات وتوزيع السلطة فضلاً عن تطوير أدوار تنظيمة للناس وتأسيس واتفاق على الأهداف إن عملية الربط هذه هي التي تدمج الأهداف المتنوعة للأنظمة الفرعية الختلفة للمنظمة لتشكيل هدف تنظيمي مشترك عن طريق صنع القرار الذي يشمل الأظظمة الفرعية المثأثرة، وهناك نوعان من المتغيرات أو غناذج من نظرية النظام: النظام المتوح والنظام المغلق ويم إغلاق النظام المغلق كما يوحي الكسم إلى البيئة وبالتالي لا ينتلى مدخلات من البيئة هو شكل قابل للتنسير بشكل كامل ويتعلق بنوع النظام الموجود في العلوم الطبيعة والاجتاعية أو الأفضل في جمع النظم الاجتاعية ، تلعب العوامل البيئة دوراً أساسياً مائمل نموذج

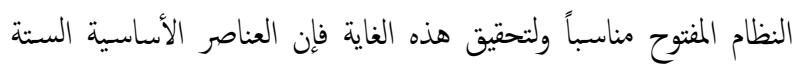
لنظرية النظم العامة وهي: النظام المتوح لمنظمة ما والإنتروبيا والسلبية
والاحتفاظ بنصبه وبالتالي لا يمكن أن يتوقع منهم أن يتصرفوا في المصلحة العامة العريضة ولكن بدلاً من ذلك سيحاولون جعل أنسهم يتمتعون بشعبية ومن ثم تعزيز قوتهم من خلال السلطة وتحسين آفاقمم لإعادة الاتنخاب (Fozzard) وإن النظرة الجوهرية لنظرية الحيار العام هي أن تخصيص (2001) الموارد وإعادة توزيعها هو نتيجة عملية سياسية ومعنى ذلك هو أن أي مناقشة في السياسة العامة بشأن الموازنة تكون فعالة من الناحية الاقتصادية إذيجب أن تؤخذ في نظرالاعتبار الجدوى السياسية لتلك السياسة ولأن كل من السياسيين والبيروقراطيين أنانيون ومتطلعون إلى أنسهم فإن عمليات الموازنة قد لا تنيد الفتراء على الإطلاق وبالتالي فإن هذه النظرية تعترف بالحاجة إلى تصحيح أوجه التصور في آليات السوق ومن ثم تضع على حد سواء الالتزام الأخلاق والقانوني على الحكومة لاقتزاح علاجات كما أنه يتبع من منظور

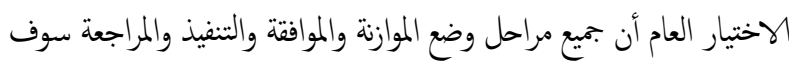
تكون متحمسة للاهتام الأناني وبالتالي ستتم عملية التخصيص بأنانية من قبل السياسي وسيتم تنغيذها بأنانية من قبل بيروقراطي تتعارض الآثار المتزتبة على


وستكون النتائج النهائية عدم الاضضباط وعدم الكفاءة وعدم المساواة والمزيد

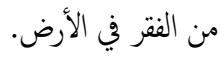

ثانياً: النظرية التنازلية Trickle-Down Theory (TDT): تنبع النظرية التنازلية

من الاعتقاد بأن تراك الثروة من قبل الأغنياء جيد للفتراء لأن بعض (TDT) الثروات المتزايدة للأغنياء سوف تتدفق إلى النقراء أي أنه يدعو إلى أن الفوائد الاقتصادية لأي سياسة سوف تثدفق من المستوى الكلي (المكومة) إلى

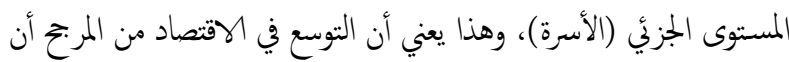
ينيد كل فرد في الجمتع تمشيا مع التشابه القائل بأن "المد المرتغن يرفح كل السفن" ويترتب على ذلك أن الجهود التي تبذلها المكومة لتحفيز النمو الاقتصادي مفيدة المجتمع على الرغ من أن هذا الجهد قد يزيد الإنفاق الحكوي وبالتالي سيتم

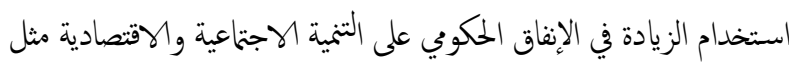
الطرق والمياه والتعليم والإعانات في تصنيع بعض السلع الأساسية للحد من الفتر وفقا لأنصار هذه النظرية أن هناك آلية انتقال بين بعض المتغيرات الاقتصادية الكلية وحدوث الفتر لذا يكن دمج العلاقة بين الموازة والحد من لمن 


\section{ج- توصيف متغيرات البحث (Search Variables Descripti)}

تعد هذه المرحلة من أهم مراحل إعداد الإموذج الإقتصادي القياسي حيث يتم فيها تحديد العلاقة بين المتغيرات الاقتصادية المعتمدة والمتغيرات التفسيرية(المستقلة) في النموذج الأقتصادي القياسي وذلك طبقاً لمططيات النظرية الأقتصادية، كما ويتم في هذه المرحلة تحديد الشكل الوظيفي الصحيح لنموذج الإنحدار من خلال تحديد المتغيرات المستقلة بكل عناية ودقة ذلك للحصول على تأثيرات جيدة على المتغير النابع ذلك أن النموذج الصحيح يؤدي إلى نتائُ جيدة وبعكسها تكون النتأُج غير دقيقة، وفي هذا البحث تم استخدم نموذج لوغارتي، وكما يلي: Logpov. $=\beta_{0} \pm \beta_{1} \log ($ Edu. $) \pm \beta_{2} \log ($ Heal. $) \pm \beta_{3} \log ($ Milita. $)+\beta_{4}$ $\log ($ Gov.dept $) \pm \beta_{5} \log ($ Tax Reve. $)+\varepsilon$ it هي نسبة عدد الفقراء الفعليين عند 1.9\$ في اليوم حسب خط الفقر الدولي. Edu. Eو نسبة الإنفاق على التعليم من GDP. Heal. Milita. Gov.dept Tax Reve.

\section{ح-الإطار القياسي المتبع في التحليل}

إن التطورات الأخيرة التي طرأت على جانب الإقتصاد القياسي بشكل عام ومجال التحليل السلاسل الزمنية بشكل خاص ركزت كثيراً على الخصائص الإحصائية وذلك بعد أن قامكل من Nelson \& plosser في عام 1982 بنشر ورقتها وأكدا من خلال ذلك في أن معظم السلاسل الزمنية لتمويل الولايات المتحدة لدها جذر الوحدة(Unit Root) والتي تعني أن معظم السلاسل الزمنية غير ثابت مما يعني أن تطبيق الأساليب التقليدية على بيانات غير ثابتة إحصائيًا فسوف يؤدي إلى تقدير الإنحدار الهامش (الزائف) وغير موثوق بها بجيث لايككن الإعتاد على نتائجها ولتجنب ذلك فإن استخدام لوحة البيانات panel data يصبح أكثر موثوقا بها والذي تم الإعتاد عليها في هذا البحث لاحتوائها على كل من السلاسل الزمنية وبيانات المقطع العرضي في الوقت ذاته ومن أجل تنجب الوقوع في هذه المشكلة وللحصول على سلاسل زمنية ثابتة عند مستوى تكمل تحدده الإختبارات فسوف
ومدخلات عملية الإنتاج والتزيز والتكمل والتغذية المرتدة والمساواة ذات صلة بشرح معظم النظم الاجتاعية بما في ذلك الموازنة النظام.

3.8

\subsection{8 قياس أثر المثغيرات المالية الاساسية على الفقر في دول العينة}

بعد تناول نظرية الموازنة العامة والفقر والعلاقة بينها، يتم التطرق في هذا المبحث الى قياس أثر المتغيرات المالية الاساسية على الفقر في دول العينة باستخدام البرنامج القياسي panel data للموذج المستخدم وذلك لغرض تحليل الإخلافات في تخصيص نسبة تلك البنود على جوانب الحياة التي تمس بشكل مباشر معيشة الأفراد ويتمثل طبيعة البيانات المستخدمة في النموذج القياسي المستخدم والمعتمد من قبل الباحث في تقدير أثر متغيرات الموازنة العامة والمتمثلة بجانبي الايرادات العامة والنفقات العامة كتنغيرات توظيحية في الحد من ظاهرة الفقر بالقياس على أساس سنوي 2010 ولكن وبالمقابل إن طبيعة قياس معدلات الفقر وخاصة خط الفقر الدولي المقاس والمعتمد من قبل البنك الدولي والذي يبلغ 1.9\% \$ في اليوم وعلى أساس القوة الشرائية لعام 2011 والتي اعتمدت من قبل الباحث كنسبة من السكان الذين يقعون تحت هذا الخط الدولي للفقر وإختيار بمحوعة من البلدان على أساس القارات وفي هذا السياق ومن أجل إكمال متطلبات البحث بشكل عام والمتطلبات القياسية بشكل خاص، شكلت البيانات إعتاداً رئيساً على البيانات التي وفرها البنك الدولي (W.B) المتمثلة بمؤشرات التنمية الدولية World Development Indicator أما فيما يخص البلدان المختارة فقد حاولت الباحثة القيام بجمع أكبر عدد مككن من البلدان وخاصة البلدان التي يتوفر فيها الفتر بشكل كير ولكن وبسبب ندرة البيانات الموجودة والمتعلقة خاصة من جانب المتغير التابع فقد تم اعتاد على ست دول نامية في أربع قارات وذات مستويات مختلفة للدخل ومصنفة وفق تصنيف البنك الدولي (www.worldbank.org) (ي وهي أوكرانيا وتصنف ضمن الشريحة الدنيا من البلدان متوسطة الدخل وتقع في أوروبا وآسيا الوسطى وأندونيسيا وتصنف ضمن الشريحة الدنيا من البلان متوسطة الدخل والتي تقع في شرق آسيا والمحيط الهادئ والبرازيل وتصنف كرد ضمن الشريحة العليا من بلدان متوسطة الدخل وكذلك بوليفيا وتصنف الشريحة الدنيا من البلدان متوسطة الدخل وهندوراس وتصنف الثريحة الدنيا من البلدان متوسطة الدخل حيث أن ثلانهم يقعون في وتقع في أمريكا اللاتينية والبحر كاريب وأخيراً زامبيا وتصنف ضمن الشريحة الدنيا من بلدان متوسطة الدخل حيث أنها تقع في أفريقيا جنوب الصحراء. 
هذا الأختبار على حساب جذر الوحدة أولاً ومن ثخ تحويل القيمة الأحصائية للتخلص من أثثار الأرتباط الذاتي على التوزيع الأحتالي للإحصائية الأختبار (Perron,1988,335) ) وبعد أخذ الإختبارين على متغيرات البحث أمكن الحصول

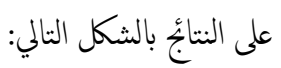

الجدول (1) ملخص اختبارات جذر الوحدة

\begin{tabular}{|c|c|c|c|c|c|}
\hline Variables & $\begin{array}{l}\text { ADF } \\
\text { Test }\end{array}$ & Probability & $\begin{array}{l}\text { PP. } \\
\text { Test }\end{array}$ & Probability & The result \\
\hline Pov. line & 95.1021 & $0.0000^{*}$ & 87.0743 & $0.0000^{*}$ & أخذ الفرق بعد \\
\hline Edu.GDP & 34.4685 & $0.0006^{*}$ & 64.8556 & $0.0000^{*}$ & مستقر بعد الخذ الفرق \\
\hline $\begin{array}{l}\text { Milit. } \\
\text { GDP }\end{array}$ & 32.1404 & $0.0013^{* *}$ & 51.8761 & $0.0000^{*}$ & أخذ الفرق بعد \\
\hline $\begin{array}{l}\text { Heal. } \\
\text { GDP }\end{array}$ & 42.4671 & $0.0000^{*}$ & 69.8349 & 0.0000 & أخذ الفرق بعت \\
\hline $\begin{array}{l}\text { Dept. } \\
\text { GDP }\end{array}$ & 36.4225 & $0.0003^{*}$ & 22.0694 & $0.0367^{* * *}$ & أخذ الفرق الأول \\
\hline $\begin{array}{l}\text { Tax. } \\
\text { GDP }\end{array}$ & 25.6148 & $0.0122^{*}$ & 33.1496 & $0.0009^{*}$ & مستقر في \\
\hline
\end{tabular}

المصدر: من عمل الباحث بالإعتاد على خرجات برنامج 10.Eviews.

من مخرجات الجدول أعلاه حيث يثير الرمز (*) إلى مستوى المعنوية عند 1\%، وأن الرمز (**) يشير إلى مستوى المعنوية 5\%، وأن (***) يشير إلى مستوى المعنوية 10\%، ويلاحظ من الجدول في أعلاه وحسب اختبار كل من ADF واختبار PP أن جميع المتغيرات غير مستقرة في المستوى وأهها تعاني من جذر الوحدة ولكن وبعد أخذ الفرق الأول لهذه المتغيرات استقرت ولكن عدا متغير نسبة الإيرادات الضريية من الـGDP حيث أنها استقرت في المستوى وأنها لاتعاني من مشكلة جذر الوحدة وتشير النتاجُ أن لنسبة عدد السكان الفعليين الذين يقعون أدنى خط الفقر عند \$1.9 في اليوم ووفقاً للتحليل القياسي مستقر بعد أخذ الفرق الأول وعند مستوى المعنوية 1\% أي أنها متكمامة من درجة الصفر ، والسلاسل الزمنية لنسبة الإنفاق العام على التعليم من الـ GDP ونسبة الإنفاق العسكري من الـ GDP ونسبة الإنفاق على الصحة من الـ ونسبة الدين الحكومي من GDP لايمكن حصولم على درجة سكون متطابقة في المستوى إلا بعد أخذ الفرق الأول لهم أما بالنسبة للإيرادات الضريبية من الـ GDP فهي مستقرة عند المستوى (ثابت) مما يشير هذه النتائج إلى أن بيانات السلسلة الزمنية
يطبق في هذه الدراسة اختبارات جذر الوحدة مثل إختبار ديكي فولر (ADF) واختبار(Philips-Perron Augmented Dickey-Fuller ويحتوي هذا البحث على أهم الإختبارات التي يتم استخدامها في نموذج لوحة البيانات وذلك للحصول على ننائج دقيقة وموثوق بها والتأكد من أنها خالية من العيوب الإحصائية المشتركة مثل الإنحار الخطي (Spurious Regression) وعدم التجانس (Heteroscedasticity) وغيرها من المشاكل الإحصائية، وكذلك يكتوي هذا على ثلاث نماذج رئسية لـPanel Data مثل اختبار نموذج التاثثرات التجميعية Pooled Regression Model (PME) واختبار نموذج الثأثيرات الثابتة Fixed Effects Model (FEM) واختبار نموذج الثأثيرات العشوائية Hausman test واختبار هوسمان Random Effects Model (REM) واختبار التشخيص diagnostic test والتي سوف نأتي على ذكر كل واحد من

$$
\begin{aligned}
& \text { هذه الإختبارات بشيء من التوضيح. } \\
& \text { خ-نتائج البحث: }
\end{aligned}
$$

• The (UNIT ROOT) Stability of Variables :

Stationarity test

يتم التأكد من استقرارية المتغرات من خلال اختبار جذر الوحدة للإستقرار لمعرفة درجة التكامل في (The (UNIT ROOT) Stationarity test) سلسلة زمنية من المتغيرات الإقتصادية قيد البحث لمعرفة ما إذا كان مستقراً أم لا ويعتبر هذا الإختبار إحدى أهم مراحل بناء نموذج الإقتصاد القياسي، حيث أن أكثر الطرق المعاصرة في تحديد استقرار البيانات هي اختبارات جذر الوحدة والذي يتم

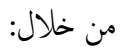

\section{اختبار ديكي فولر الموسع: Augmented Dickey-Fuller (ADF) ويتم اختبار ديكي فولر الموسع الذي تم تطويره في عام 1981}

\section{The Philips-Perron Test(PP) : أختبار فيليس بيرون:}

قام كل من فيلبس وبيرون في عام 1988 بتطوير تعميم طريقة ديكي-فولر الموسعة حيث أنها تسمح بوجود ارتباط ذاتي في حد الخطأ، ويعتبر هذه الطريقة هي تعديل لاختبارديكي-فولر الذي يأخذ في الإعتبار قيود أقل على حد الخطأ حيث يسمح لحد الخطأ العشوائي بأن يكون غير مستقل بشكل قليل مع توزيع غير متجانس، ويعتمد 
سلبي وذو دلالة إحصائية جيدة في جميع المواصفات والذي يبين على أن النموذج يتقارب

$$
\text { نخو التوازن حيث أن سرعة التعديل هو 43\%. }
$$$$
\text { إن نماذج لوحة البيانات تأتي في ثلاث أشكال رئسية: }
$$

\section{أولاً: نوذج الإنحدار المجمع أو التجميعي Pooled Regression Model (PME)}

يعتبر هذا النموذج أحد أبسط الناذج في لوحة البيانات حيث أن جميع المعلمات

فيها (i)

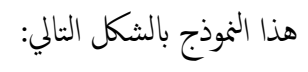

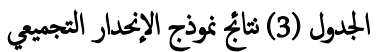

\begin{tabular}{|c|c|c|c|c|}
\hline Log Pov. 1.9\$ & Coef. & Std.Err & $\mathrm{T}$ & $\mathrm{P}>|\mathrm{t}|$ \\
\hline Log Edu.GDP & $-1.511495^{*}$ & 0.248496 & -6.08 & 0.000 \\
\hline Log Milit. GDP & $-1.631313^{*}$ & 0.335685 & -4.86 & 0.000 \\
\hline Log Heal. GDP & $0.935811^{* *}$ & 0.432638 & 2.16 & 0.0332 \\
\hline Dept. GDP & $0.008673^{* *}$ & 0.003444 & 2.52 & 0.0903 \\
\hline Tax. GDP & $-0.138371^{* * *}$ & 0.080808 & -1.71 & 0.0903 \\
\hline Cons. & $4.804301^{*}$ & 1.035417 & 4.64 & 0.000 \\
\hline
\end{tabular}

R-squared=0.56 prob> F = 0.0000 Eviews.10. المصدر: من اعداد الطالب بالإعتاد على خخرجات

ملاحظة: * معنوية عند 1\%، ** معنوية عند 5\%، *** معنوية عند 10\%.

\section{Fixed Effect Model (FEM) ثانياً: نموذج الثأيرات الثابتة}

مهدف نموذج الثأثيرات الثابتة لمعرفة سلوك كل بموعة من البيانات بشكل منفصل عن طريق جعل معلمة المقطع م متفاوتة من مجموعة لأخرى أي سلوك كل دولة على حدا مع بقاء معاملات الإنحدار ثابتة لكل بموعة من البيانات والتي تعني أن التعامل سوف يكون مع حالة عدم التجانس بين



الجدول (4) نتابُج نوذج الإنحدار الثابت

\begin{tabular}{|c|c|c|c|c|}
\hline Log Pov. 1.9\$ & Coef. & Std.Err & $\mathrm{T}$ & $\mathrm{P}>|\mathrm{t}|$ \\
\hline Log Edu.GDP & $-0.951093^{*}$ & 0.363627 & -2.62 & 0.0105 \\
\hline Log Milit. GDP & $0.611262^{* *}$ & 0.302380 & 2.02 & 0.0464 \\
\hline Log Heal. GDP & $-1.285442^{* * *}$ & 0.667607 & -1.93 & 0.0575 \\
\hline Dept. GDP & $0.007033^{*}$ & 0.001616 & 4.35 & 0.000 \\
\hline Tax. GDP & $-0.194859^{*}$ & 0.033798 & -5.77 & 0.000 \\
\hline Cons. & $8.013619^{*}$ & 0.948096 & 8.45 & 0.000 \\
\hline
\end{tabular}

prob> F = $0.0000 R^{2}=0.94$ Eviews 10 المصدر: من اعداد الطالب بالإعتاد على مخرجات

ملاحظة: * معنوية عند 1\%، ** معنوية عند 5\%، ***منوية عند 10\%.
متكاملة ومتطابقة بدرجات مختلفة، وبذلك يكن اجراء اختبارات أخرى بعد استقرار

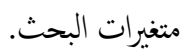

Cointegration test : اختبار النكمل المشترك بين المثغيرات: درس Entrof في عام 1997 الآثار الثابتة للإنحدارات الزائفة عندما يتضمن النموذج الحقيقي مناحي عشوائية مستقلة مع أو بدون الإخرافات، عندما تكون N م N مكون محدودة، إذ قد تكون آثار الإنحدار ظاهر غير حقيقية ولأن نموذج الآثار الثابتة قد يكون زائفاً بحيث تكون الإستدلال على أساس قيمة t مضللة، استمدكل من Kao و Phillips and Moon في عام 1999، حيث أن فكرة النكمل المشترك تقوم على المفهوم الإقتصادي للخصائص الإحصائية للسلاسل الزمنية المقطعية وأنها تنص على أن المتغيرات الإقتصادية التي تفتزض النظرية الإقتصادية على وجود علاقة توازنية طويلة الأجل بنها بحيث أن هذه المتغيرات حتى ولو ابتعدت عن قيم توازهها في الفترة القصيرة فإنه وبفعل القوى الإقتصادية يكن تصحيح هذا التباعد من خلال إعادة هذه المتغيرات الإقتصادية للتحرك نحو التوازن طويل الأجل، ولإن متغيرات البحث متكلماة ومتطابقة بدرجات مختلفة فمكن اجراء اختبار ARDL والحصول على النتائُ

\section{ARDL الجدول (2) نثائُ النكامل المشترك حسب}

Dependent Variable: D(POVERTY)

Date: O6/10/18 Time: 21:46

Sample: 20012015 : $21: 46$

Maxmum dependent lags: 1 (Automatic selection)

Model selection method: Akaike info criterion (AIC)

\begin{tabular}{|c|c|c|c|c|}
\hline \multicolumn{5}{|c|}{ Long Run Equation } \\
\hline $\begin{array}{c}\text { EX_EDUCATION } \\
\text { EX_MILITARY } \\
\text { EX_HEALTH } \\
\text { DEBT } \\
\text { TAX_REVENUE }\end{array}$ & $\begin{array}{r}-3.206747 \\
3.074852 \\
3.485173 \\
-0.043096 \\
0.570581 \\
\end{array}$ & $\begin{array}{l}1.038918 \\
0.886687 \\
1.338404 \\
0.027434 \\
0.204182 \\
\end{array}$ & $\begin{array}{r}-3.086622 \\
3.467798 \\
2.603977 \\
-1.570873 \\
2.794476 \\
\end{array}$ & $\begin{array}{l}0.0033 \\
0.0011 \\
0.0122 \\
0.1226 \\
0.0074 \\
\end{array}$ \\
\hline \multicolumn{5}{|c|}{ Short Run Equation } \\
\hline $\begin{array}{c}\text { COINTEQO1 } \\
\text { D(EXEDUCATION) } \\
\text { D(EX EMILITARY } \\
\text { D(EX HEALTH) } \\
\text { D. HEBT) } \\
\text { D(TAX_REVENUE) } \\
\text { C } \\
\end{array}$ & $\begin{array}{l}-0.341773 \\
4.888240 \\
-5.885054 \\
-2.012493 \\
-0.123343 \\
-0.242524 \\
0.664563 \\
\end{array}$ & $\begin{array}{l}0.080852 \\
3.045541 \\
2.221524 \\
1.097087 \\
0.188061 \\
0.185371 \\
2.969112 \\
\end{array}$ & $\begin{array}{r}-4.227153 \\
1.605049 \\
-2.649106 \\
-1.834396 \\
-0.655869 \\
-1.308317 \\
0.223826 \\
\end{array}$ & $\begin{array}{l}0.0001 \\
0.1149 \\
0.0108 \\
0.0727 \\
0.5150 \\
0.1969 \\
0.8238 \\
\end{array}$ \\
\hline $\begin{array}{l}\text { Mean dependent var } \\
\text { S.E. of regression } \\
\text { Sum squared resid } \\
\text { Log likelihood }\end{array}$ & $\begin{array}{r}-0.693333 \\
3.158593 \\
488.8589 \\
-147.3472\end{array}$ & \multicolumn{2}{|c|}{$\begin{array}{l}\text { S.D. dependent var } \\
\text { Akaike info criterion } \\
\text { Schwarz criterion } \\
\text { Hannan-Quinn criter. }\end{array}$} & $\begin{array}{l}3.532603 \\
4.048900 \\
5.304362 \\
4.556379\end{array}$ \\
\hline
\end{tabular}

Fixed regressors: C B T TAX_REVENUE

Number of models evalulated: 1,1

Note: final equation sample is larger than selection sample

\begin{tabular}{llll}
\hline Variable Coefficient & std. Error $t$-Statistic Prob.
\end{tabular}

*Note: p-values and any subsequent tests do not account for model
selection.

من ننائُ الجدول في أعلاه يلاحظ بأنه في حالة المدى الطويل وأن جميع المتغيرات معنوية عند المستوى 5\% كما وأن إثارة المثغيرات هي متطابقة مع النظرية الإقتصادية، كما سنأتي إلى ذكره في ناذج الإقتصاد القياسي لـ Panel Data، كما وييين الجدول في ذات الوقت ننائُ تحليل المدى القصير والنتائج تكشف عن أن معامل تصحيح الخطأ هو 
ويكن الحكي على الإختبار عن طريق إحصائية ماكينون Mackinnon فإذا كانت قيمة أكبر من مستوى معنوي 5\% ن Value)

$$
\text { ملائمة نموذج الإنحدار التجميعي ونرفض الفرضية البديلة. }
$$

\section{جدول (6) نتاجُ اختبار مضاعف لاكوانج LM للمفاضلة}

\begin{tabular}{|c|c|c|}
\hline Type of test & Statistic & Prob \\
\hline LM & 2.124765 & 1.0000 \\
\hline
\end{tabular}

المصدر: من اعداد الطالب بالإعتمد على مخرجات Eviews 10.

فأن نتائج الجدول أعلاه والتي تؤدي إلى قبول فرضية العدم والتي يبين أن النموذج الملائم هو نموذج الإنحدار التجميعي ورفض الفرضية البديلة التي يدل على ملائمة



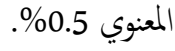

\section{Hausman test ثانياً: اختبار هاوسمان}

تم تطوير هذه الإحصائية من قبل Hausman في عام 1978 حول الإختيار بين

نماذج الآثار الثابتة والآثار العشوائية وبالتالي إستخداهه في التحليل إذ يعطي دليلاً للباحث حول الموذج الأفضل والأنسب أي أنها تختبر بشكل أساسي ما إذا كانت شروط الخطأ مرتبطة بالإنحدار أي عندما تكون قيمة الإحتاية P أقل من 0.05 فإن النموذج الأمثل هو نموذج التأثيرات الثابتة وبالعكس يكون النوذج الأمثل هو نموذج

$$
\text { التأثيرات العشوائية، }
$$

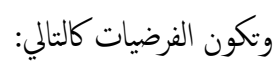

Ho نموذج التأثيرات العشوائية هو الملائم.

ن : نوذج الثأثيرات الثابتة هو الملائم.

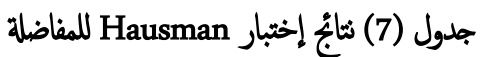

\begin{tabular}{|c|c|c|c|c|}
\hline Log Pov. 1.9\$ & $\begin{array}{c}\text { B } \\
\text { Fixed }\end{array}$ & $\begin{array}{c}\text { B } \\
\text { Random }\end{array}$ & $\begin{array}{c}\text { (b-B) } \\
\text { Difference }\end{array}$ & $\begin{array}{c}\text { Sqrt(diag(V-b- } \\
\text { V-B)) } \\
\text { S.E. }\end{array}$ \\
\hline Log Edu.GDP & -0.951093 & -1.511495 & 0.122703 & 0.2829934 \\
\hline $\begin{array}{c}\text { Log Milit. } \\
\text { GDP }\end{array}$ & 0.611262 & -1.631313 & 0.074059 & 0.1038462 \\
\hline $\begin{array}{c}\text { Log Heal. } \\
\text { GDP }\end{array}$ & -1.285442 & 0.935811 & 0.416839 & 0.547637 \\
\hline Dept. GDP & 0.007033 & 0.008673 & 0.000001 &. \\
\hline Tax. GDP & -0.194859 & -0.138371 & 0.000136 &. \\
\hline
\end{tabular}

Probability > chi2 = 0.0000 .Eviews 10 المدر: من اعداد الطالب بالإعتاد على مخرجات
Random Effect Model (REM) الثاً: نموذج الثأثيرات العشوائية

يكون حد الخطأ ع في نموذج التأثيرات الثابتة ذا توزيع طبيعي متوسطه يساوي صفر والتباين يساوي Oع2، ومن أجل أن تكون معلمات نموذج التأثيرات الثابتة صحيحة وغير متحيزة فني العادة تفترض بأن تباين الخطأ ثابت (متجانس) لجميع البيانات المقطع العرضي، ولاتعاني من ارتباط ذاتي خلال الفترة الزمنية بين بمموعة بيانات المقطع العرضي في الوقت المحدد وهذا النموذج هو ملائم ومناسب عند وجود خلل في إحدى الفرضيات المذكورة في نموذج الثأثيرات الثابتة (Gujarati, 2003). جدول (5) نتائج نموذج الإنحدار العشوائي

\begin{tabular}{|c|c|c|c|c|}
\hline Log Pov. 1.9\$ & Coef. & Std.Err & $\mathrm{Z}$ & $\mathrm{P}>|\mathrm{z}|$ \\
\hline Log Edu.GDP & $-1.511495^{*}$ & 0.097576 & -15.49 & 0.000 \\
\hline Log Milit. GDP & $-1.631313^{*}$ & 0.131812 & -12.38 & 0.000 \\
\hline Log Heal. GDP & $0.935811^{*}$ & 0.169882 & 5.51 & 0.000 \\
\hline Dept. GDP & $0.008673^{*}$ & 0.001352 & 6.41 & 0.000 \\
\hline Tax. GDP & $-0.138371^{*}$ & 0.031730 & -4.6 & 0.000 \\
\hline Cons. & $4.804301^{*}$ & 0.406573 & 11.82 & 0.000 \\
\hline
\end{tabular}

prob> F = $0.0000 R^{2}=0.56$ Eviews 10. ملاحظة: * معنوية عند 1\%، ** معنوية عند 5\%، *** معنوية عند 10\%.

Tests of differentiation between models ث- اختبارات الثفاضل بين الناذج ولأجل إيجاد النموذج الملائم يجب القيام باختبارات تحديد النموذج الملائم وذلك عند استخدام Panel Data أو مايسى باختبارات التحديد، والتي هي:

أولاً: اختبار مضاعف لاكوانج :Breusch \& Pagan Lagrangian :LM Multiplier Test حيث أن هذا الإختبار يساعد الباحث في الإختيار بين نموذج الآثار العشوائية ونموذج الإنحدار التجميعي أو المجمع كما اقترهه Breusch و Pagan في عام 1980

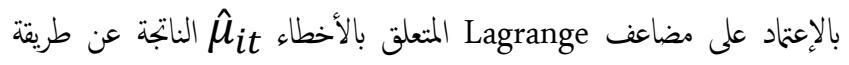

$$
\begin{aligned}
& \text { المربعات الصغرى الإعتيادية. } \\
& \text { والفرضيات تكون كالنالي: } \\
& \text { ب } \\
& \text { H }
\end{aligned}
$$


ولها علاقة سلبية مع لوغارتم خط الفقر الدولي إذ أنه بزياد نسبة الإنفاق على التعليم من الـ GDP فإها سوف تؤدي إلى إنخاض لوغارتم خط الفقر بنسبة 0.95\% وهذا حسب النظرية الإقتصادية إذ أن زيادة الإنغاق على التعليم وخاصة بالنسبة للمراحل البدائية فإن نسبة الفقراء الذين يستفادون من هذا يكون في زيادة، وبالنسبة للوغارتم الإنفاق العسكري من الـ GDP والذّ يكون معنوي عند مستوى 5\% عع إثارة موجبة والتي تدل على العلاقة الطردية بين نسبة الإنفاق العسكري والفقر والتي كما ذكر سابقاً بأن الإنفاق العسكري هو سلاح ذو الحدين والتي قد يكون لها آثار إيجابية على معدلات الفقر خاصة في الأمد الطويل والتي يككن الإستفادة من المصانع والمستشفيات العسكرية والطرق التي تبنى لأغراض عسكرية وغيرها من العمليات التي يمكن الإستفادة منها بعد الحرب أي في الأمد الطويل وحسب ماموجود هنا فإنه بزيادة الإنفاق العسكري من الـ بنسبة 1\% فإن هذا يؤدي إلى زيادة نسبة عدد الفقراء الذين يقعون تحت خط ري رل الفقر الدولي بنسبة 0.62\% وخاصة في الأمد القصير وفي أوقات الحرب بسبب التخصيصات الكبيرة الذي يوفرها الحكومات وخاصة بالنسبة للدول النامية والتي هي أغلها مستوردة من الخارج وعدم الإستفادة منها في الداخل أي عدم وجود مصانع حربية أو مستشفيات عسكرية تقدم خدمات جيدة بحيث يمكن الإستفادة منها مستقبلاً كما وإن أغلب مايستورده الدول النامية من أغراض عسكرية هي إستهلاكية، ونسبة الإنفاق على الصحة منGDP والتي هي معنوية عند مستوى 10\% وذو الإثارة السالبة التي تدل على أنها وبزيادتها بمقار 1\% فإن نسبة عدد الفقراء الذين يقون تحت خط الفقر سوف ينخفض بنسبة 1.28\% والتي تتفق هذه العلاقة مع النظرية الإقتصادية ومع الدراسات التي طبقت على هذا المتغير ، وبالنسبة للدين الحكوي كنسبة من الـ GDP والتي هي معنوية عند مستوى 1\% والتي لها إنشارة موجبة مع لوغارتح خط الفقر والتي تعني أنه بزيادة الدين العام بنسبة 1\% فإها تؤدي إلى زيادة نسبة عدد الفقراء من يقعون تحت خط الفتر الدولي بنسبة 0.007\% وذلك لطبيعة البلدان التي تم قياس الفقر فيها حيث أن زيادة لجوء المكومات إلى الدين فانها تعني ضمناً ضعف آدائها الملالي خاصة من جانب الإنفاق العام كما وأن أغلب الدول النامية تقوم باللجوء إلى الدين لأغراض الإستهلاك الحكوي والعام وليس لأغراض الإنتاج مما يساهم بشكل مباشر أو غير مباشر في زيادة عدد الفقراء خاصة إذا ما قورن بعدم إمكانية هذه الدول بدفع ماعليها من دين في وقتها المعين أو المحدد، وبالنسبة للإيرادات الضريبية كنسبة من الـ GDP والتي هي معنوية عند مستوى 1\% وبإشارة سالبة مع لوغارتم خط الفقر حيث أنه
من الجدول أعلاه تظهر نتيجة إختبار Hausman الذي يستخدم هذا الإختبار لاختيار النموذج الملائم بين كل من نموذج الآثار الثابتة والعشوائية، حيث يوضح العمود b قيم معاملات المتغيرات في نموذج الإخدار الثابت، أما العمود B فيوضح قيم معاملات المنغيرات في نموذج الإنحدار العشوائي، بينا العمود (b-B) فيبين الفرق بين نموذج الثاثيرات الثابتة وموذج الثأثيرات العشوائي، ويلاحظ من قيمة الإحتالية P بأن النموذج الأمثل هو نموذج الآثار الثابتة وذلك لأهها أقل من 5\% وتكون ذات كفاءة عالية مقارنة مع نموذج الآثار العشوائية، والتي تنص فرضية البديلة على وجود ارتباط بين الآثار الثابتة

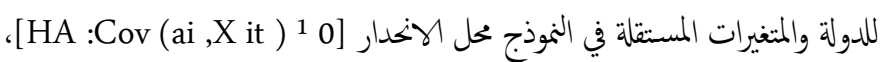
حيث أن القيم المقدرة لمعاملات الميل في REM تكون غير متسقة بينا هذه القيم في FEM تكون متسقة وذات كفاءة كما وأن اختيار FEM هو الإختيار الأنسب. ج- تحليل نتاجُج المفاضلة ومناقثتها إن القيام بعملية التحليل والمناقشة بعد التطرق للجانب النظري وإجراء الحسابات هو عصارة كل الدراسات، لذا لابد من الإشارة للنتائُ التي تم وصول الباحث الهيا في المرحلة

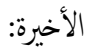

أولاً: تحليل نتاجُ المفاضلة بين الناذج: من خلال الجدول رقّ (7) يبين القيم الإحتالية لاختبار Hausman بين نموذجي الأثر الثابت والأثر العشوائي والتي كانت أقل من 5\% ما يدل على أن نموذج الآثار الثابتة هو الملائم لدراسة أثر متغيرات الدراسة على الحد من ظاهرة الفقر وعلى تقليل أعداد الأفراد الذين يعيشون تحت خط الفقر الدولي، ويككن من الجدول (4) المتعلق بالآثار الثابتة معرفة بأن القيم الإحتالية للمعلمات الجزئية والكلية لنموذج الإنحار الثابت هي مقبولة احصائياً وذلك لأن القيم الإحتالية هي أقل من 5\% و 10\%،قيمة R-squared لهذا النموذج هو 94\% والذي يدل على إمكانية تفسير المتغيرات المالية من التأثير على لوغارتم خط الفقر الدولي بنسبة 94\% وأن 6\% تعود لمتغيرات أخرى لم يتضمنها النموذج وذلك لأن الفقر هو المتغير الذي يتأثر بالسياسات الحكومية بشكل كير بسبب إعتاد أفراد هذه الدول بشكل رئيسي على القطاع العام والذي يتميز القطاع الخاص في هذه الدول بصغر جمها وعدم تأثيرها إلا بالشكل الضئيل جداً مع أن الفقر وبشكل عام يتثأثر بكل جوانب الحياة وليس بالجانب الملالي الحكوي فقط ولكن هذه النسبة تبين الأهمية الكبيرة للقطاع العام في حياة أفراد الدول النامية والذين يعتمدون على إمكانيات وما تقدمه حكومات هذه الدول لأفرادها، كما وتشير النتائج إلى أن لوغارتم سبة الإنفاق على التعليم من GDP مستقر عند 1\% 
توزيع LM بشكل مقسم كربع مع درجات الحرية 2N-1)/2، وفق فرضية العدم مع ثبات N و و $T \rightarrow \infty$ وفي سياق تقدير الإنحدار الغير مرتبط اقتزح $\leftarrow$ T SN Breusch \& Pagan 1980 م حيث من المرجح أن يظهر هذا الإختبار تشوهات كبيرة الحجم في حال أن كانت

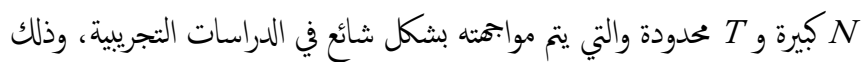
لأن إحصاء LM لايتم توسيطه بشكل صحيح في الحالات التي تكون فيها Tحدودة

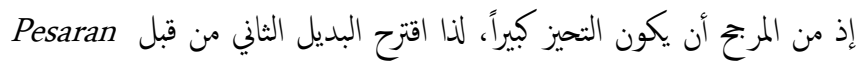

.Pesaran, 2004, 4-5 ) ، 2004

ثانياً: اختبار Pesaran CD: وأظهرت أنه في ظل فرضية العدم لعدم وجود مقطع عرضي معتمد الكفاية، على عكس إحصاء LM حيث أن إحصاء CD تعني صفر عند القيم الثابنة


الإختبارات السارية (Hoyos \& Sarafidis, 2006, 484-486)، كما تم الأشارة سابقاً في أن البيانات المقطعية للمتغيرات المستقلة هو أكثر مشكلة في لوحة بيانات كبيرة أي في سلاسل زمنية 20-30 سنة من لوحة بيانات صغيرة، وإن اختبار باساران Pasaran CD للبيانات المقطعية للمتغيرات المستقلة والذي يستخدم لمعرفة فيا إذا كان البوايق مترابطة أم لا، وبامكان هذا الإختبار المتعلق بالبواقي أن يتحيز في النتأُج والذي يسمى أيضاً الارتباط المعاصر وتشير فرضية العدم إلى أن

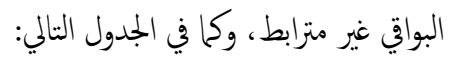

\section{جدول (8)}

\begin{tabular}{|c|c|c|}
\hline Type of test & Statistic & Prob \\
\hline Preusch-Pagan LM & 54.25043 & 0.0000 \\
\hline Pesaran CD & -0.302318 & 0.7624 \\
\hline
\end{tabular}

المصدر: من اعداد الطالب بالإعتاد على مخرجات Eviews 10.

يوضح الجدول أعلاه ننائج اختبار الكشف عن الإرتباط المعتمد العرضي بين البواقي من خلال اختبارين الإختبار Preusch-Pagan LM حيث يبين هذا الإختبار مشكلة الإرتباط بين البواقي بسبب كبر مشاهدات الدراسة حيث أن مستوى المعنوية هي أقل من 5\% والني يبين معاناة النموذج من مشكلة الأرتباط المتعدد

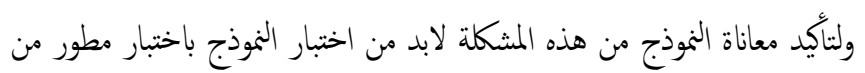

زيادة الإيرادات الضريبة بنسبة 1\% فإن هذا يؤدي إلى إخفاض لوغارتم خط الفقر الدولي بنسبة 0.2\% بسبب طبيعة فرض الضرائب في الدول النامية والتي تقع أغلها على شريحة الأغنياء وبالتالي إستفادة الفقراء من الخدمات التي تقدها الدولة بهذه

$$
\text { الضرائب، وبذلك تكون المعادلة المقدرة حسب هذا النموذج هي: }
$$
Log pov.= 8.01- 0.95 Log Edu.+ 0.62 Log Milit.- 1.28 Log Heal.+ 0.007 Log Dep. - 0.2 Log Tax.

ح- إختبارات التشخيصية: Diagnostic test على الرغخ من المزايا العديدة التي تتميز بها بيانات السلاسل الزمنية المقطعية على غيرها من البيانات إلا أنها لاتخلو من الأخطاء التي قد تنج بسبب وجود صدمات مشتركة ومكونات غير ملحوظة والتي تصبح في نهاية المطاف جزءاً كبيراً من الأخطاء إلى جانب عدم وجود نمط معين من المكونات المشتركة أو الإعتاد المكلني والتي قد يرجع سبب ذلك إلى ماثهده العالم من تكلمل اقتصادي ومالي بين البلدان والكيانات المالية والتي تعني ضمناً وجود ترابط قوي بين الوحدات الإقتصادية والتي من الممكن أن يُّسر على نحو مماثل الصدمات الشائعة من خلال المعايير الإجتاعية وتأثيرات الأحياء وغيرها من العوامل المشتركة الغير ملحوظة، ويتم إجراء هذه الإختبارات على نموذج الإندار وذلك لاهميتها مثل اختبار عدم التجانس Heteroscedasticity Test واختبارات المقطع Pesaran scald LM وBreusch- Pagan العرضي لبواقي مثل 1980 وذلك لضان أن ننائُ البيانات التي تم تحليلها هي نناجُم موثوقة ومقبولة Pesaran CD, ويكن الإعتاد عليها، مثلاً عند حدوث حالة عدم التجانس قد تلغي أهمية الإختبار الإحصائي التي تفتزض أن المتبقي غير مترابط وذو توزيع طبيعي وأن تأثير التباين لايتغير ، ولاتخاذ القرار حول أي الناذج هي أكثر دقة يستخدم اختبار مشترك لمعرفة ما إذاكان المتغيرات الوهمية لجميع السنوات تساوي صفر، فإذا كانت احتالية F أكبر من 0.05 فيكون هنالك فشل في رفض الباطل لمجيع السنوات التي تساوي صفرا، وبالتالي فليس هنالك حاجة لمتغير الأثر الثابتة في هذه الحالات كن التالي: أولأ: اختبار Breusch \& Pagan LM للمقطع العرضي المتمّد: في معادلة الإنحدار الخطي بسياق التي تكون فيها ثنابت أو محدود و T T T، اقترح كل من Breusch \& Pagan 1980 التي تتسم بسهولة حسابها ولايتطلب تقدير النظام لنموذج الإنحار الخطي، ويتم 
ويكن الكشف عن هذه المشكلة بعدة اختبارات وبشكل عام يوجد ثلاث أنواع من الإختبارات الكلاسيكية: الأول: مضاعف لاكوانج LM أو درجة كفاءة التي تستخدم في التقديرات المحدودة (فرض الفرضية الصفرية) أي المقيدة، الثاني : اختبار Wald: التي تستخدم في التقديرات الغير المقيدة (عدم فرض الفرضية الصفرية)، الثالث: نسبة الإحتال Likelihood Ratio LR: والتي تستخدم في التقديرات المقيدة وغير المقيدة، والتي تكون عادة كفوهة ولكنها قد تعطي ننائج ختلفة في العينات الصغيرة، ويتم توزيع كل منها حسب X مع درجات الحرية المقدمة من خلال عدد من القيود، وبذلك سوف يُستخدم في هذه البحث اختبار LR لسهولنه وكفاءته(Smith, 2016, 19)، حيث تم استخدام هذا الإختبار من قبل Rutemiller \& Bowers عام 1968 وأيضا من قبل Harvey عام 1976 في ورقة groupwise heteroscedasticity paper، يككن تحديد وظيفة الإحتمال بافتراض الوضع الطبيعي لحالة عامة حيث أن و لحالة عامة ولفروق مختلفة.

\section{جدول (9) نتابُج اختبار عدم التجانس}

\begin{tabular}{|c|c|c|}
\hline Type of test & Statistic & Prob \\
\hline LR & 8.673402 & 0.1928 \\
\hline
\end{tabular}

يلاحظ من خلال جدول أعلاه أن قيمة LR قد بلغت (8.673402) وهي ذات دلالة أحصائية غير معنوية حيث أن Prob. LR =0.1928 وهي أكبر من 0.05\%, وبذلك فإننا نقبل فرضية العدم for all iH ن مشكلة عدم التجانس. دا اختبار Jarque-Bera Jarque-Bera normality للتوزيع الطبيعي:

يتحقق اختبار جالك- بيرا الطبيعي من وجود البواقي، حيث أنه في الواقع لدى JB توزيع ( مع درجتين من الحرية X2) X ل لنا نقبل فرضية العدم في حالة $J B<$ مع الخطأ ع إذا فقط إذا كان $H_{0}: S=0, K=3$ ع.
خلال الإختبار الثاني والذي طوره Pesaran لتفادي المشاكل الذي يواجه الباحث عند استخدام اختبار Preusch-Pagan LM للدراسات التي تكون عدد مشاهداتها كبيرة وأكثر من 30 مشاهدة ويتثثل جوهر هذا الإختبار في معرفة ما إذا

$$
\begin{aligned}
& \text { كان النموذج يعاني من الإرتباط العرضي والتي تتضمن فرضيتين: } \\
& \text { Ho }
\end{aligned}
$$

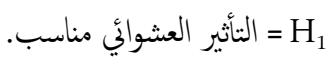

إذا كانت قيمة P أكبر من 5\% ، فسب اختبار LM يوجد مشكلة الترابط بين المقاطع العرضية بسبب التشوهات والتهيزات الكبيرة التي تخلفها هذه الإحصائية والتي تدل على رفض الفرضية الصفرية التي تدل على عدم وجود الإرتباط المقطع العرضي بين البقايا ، ويلاحظ من الجدول معالجة هذه المشكلة من ققبل مesaran لإحصاءة المطور والمعاصر الذي طوره لتفادي المشاكل التي تتعرض لها اختبار LM عندما تكون بيانات السلاسل الزمنية المقطعية كبيرة أو محدودة ويلاحظ بأن سبته بلغت 0.76 والتي تدل على قبول فرضية العدم في عدم وجود مشكلة الإرتباط المعتمد للمقاطع العرضية بين البقايا.

\section{خ- اختبار عدم التجانس Heteroscedasticity test} تعني تباين التجانس أن قيم البوايق العشوائية تتوزع توزيعاً متجانساً طبيعياً حول أي قيمة من قيم المتغير المستقل (X) نتيجة الإختبارات الإحصائية أي أن

$$
\sigma_{U_{1}=}^{2} \sigma_{U_{2}=}^{2} \sigma_{U_{3}=\cdots \ldots \ldots \ldots . .}^{2}=\sigma_{U_{n}}^{2}
$$

وحدوث مشكلة عدم ثبات تجانس التباين تعني عدم ثبات تجانس التباين بالنسبة لمجتمع الإحصائي أي أن:

$$
\sigma_{U_{1} \neq}^{2} \sigma_{U_{2} \neq}^{2} \sigma_{U_{3} \neq \cdots \ldots \ldots \ldots \ldots}^{2} \sigma_{U_{n}}^{2}
$$

تظهر هذه المشكلة عندما تختلف انحرافات قيم المشاهدة الحقيقية عن الخط المقدر إذا تغير قيم المتغير المستقل والذي يُعرف بـ(heteroscedasticity) (ادريوش، 20132014، 75)، حيث أن فرضية العدم Ho تعني أن حد الخطأ لها تباين ثابت والتي تعني لها تجانس، وبالنالي رفض فرضية العدم إذا كانت قيمة P أقل من 5\% قيمة حرجة،

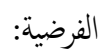
$: \sigma_{i}^{\wedge 2}=\sigma^{\wedge 2}$ for all $\mathrm{i} H_{0}$ $: \sigma_{i}^{\wedge 2} \neq \sigma^{\wedge 2}$ for all i $H_{1}$ 
الحرب بسبب التخصيصات الكبيرة الذي يوفرها حكومات هذه الدول إلى جانب

$$
\text { استهلاك الموارد وخاصة المستوردة. }
$$

iv الفقر الدولي وذلك لطبيعة البلدان التي تم قياس الفقر فها حيث أن زيادة لجوء الحكومات إلى الدين والتي تعني ضمناً ضعف آدائها الملالي خاصة من جانب الإنفاق العام ويتم عادة اللجوء إلى الدين لأغراض الإستهلاك الحكومي والعام وليس لأغراض الإنتاج مما يساهم بشكل مباشر أو غير مباشر في زيادة عدد الفقراء خاصة إذا ما قورن بعدم إمكانية هذه الدول بدفع ماعليها من دين في وقتها المعين أو المحدد. وأظهرت النتائُ أن للإيرادات الضريبية تأثثر ايجابي ومعنوي في تخفيض عدد .v السكان الذين يقعون تحت خط الفقر الدولي حيث توفر من خلالها هذه الحكومات القيام بالمجلات الإنتاجية والخدمية لصاح العامة.

10. المقترحات:

i

بالنسبة لقطاع الخدمات الإجتاعية والتي لها تأثير مباثر على حياة الفقراء. ii

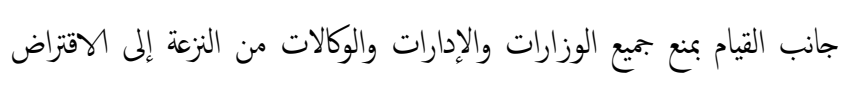
وتوجيهم في حال الحاجة إلى الإقتراض خاصة إذاكان لتنفيذ هذه المشاريع لها تأثير إيجابي مباشر على الاقتصاد إلى جانب ضرورة استكشاف خيارات التمويل الداخلي مثل السندات وأذونات الحزانة والاقتزاض المحلي قبل الاقتزاب من المصادر الخارجية.

iii بالإضافة إلى الأحكام التقييدية الأخرى في الموازنة وستمكن هذه الإصلاحات من الثأثير بشكل إيجابي على أداء الموازنة والاقتصاد والسكان. iv بنود محددة ومنها مايخص حاجة محددة للفقراء وتخصيص الموارد لتبية هذه الحاجة المحددة والتي يعتبر أحد السبل لضان وصولها إلى شريحة الفقراء دون الأغنياء. v. تعزيز المحلة ضد الفساد لضمان النجاح في تطبيق بنود الموازنة والحد من الفقر.
وتحسينه إذ يقوم نموذج انحدار البيانات السلاسل الزمنية المقطعية على جملة من الفرضيات التي تتضمن صلاحية استخدام النموذج في عملية التنبؤ وفي اختبار فرضية الدراسة والتي تتمثل في أن الأخطاء العشوائية تتبع التوزيع الطبيعي ولايوجد ارتباط ذاتي بين البواقي، وان ما يؤكد على صلاحية النموذج هو اختبار التوزيع الطبيعي

للأخطاء العشوائية،

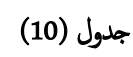



حيث يمكن ملاحظ الجدول أعلاه والذي هو اختبار التوزيع الطبيعي (Jarque-Bera) للأخطاء العشوائية في نموذج التأثيرات الثابتة والشكل أعلاه يوضح نتيجة هذا الإختبار ويؤكد من خلال القيمة الإحتالية (p-value) حيث أنها تساوي (0.627419) وأكبر من القيمة المعنوية 0.05 والذي يبن أن الأخطاء العشوائية تتبع التوزيع الطبيعي.

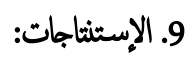
i إن النسب التي حصل عليها هذه الدول في الجانب القياسي من البحث تبين الأهمية الكبيرة للقطاع العام في حياة أفراد الدول النامية والذين يعتمدون على إمكانياتهم وما تقدمه حكومات هذه الدول لأفرادها، وإهال القطاع الخاص. ii التعليم والصحة هي في زيادة بسبب معنويتها وعلاقتها العكسية مع الفقر والني جاء طبقاً للنظرية الإقتصادية. iii معدلات الفقر خاصة في الأمد الطويل من خلال الإستفادة من المصانغ والمستشفيات العسكرية والطرق التي تبنى لأغراض عسكرية وغيرها من العمليات بعد الحرب إلا أنه وفي هذا البحث يؤدي زيادة الإنفاق العسكري إلى زيادة نسبة عدد الفقراء الذين يقعون تحت خط الفقر وخاصة في الأمد القصير وفي أوقات 
4- okpanachi Joshua and Mohammed nma ahmed, budget target setting and effective performance measurement in Nigerian hospitality industry, journal of finance and economics, published by science and education center of north America, departments of economics and management sciences faculty of arts and social sciences Nigerian April, 27.2013.

5- Poverty and Transport, A report prepared for the World Bank in Collaboration with DFID, David Booth, Lucia Hanmer \& Elizabeth Lovell, Odi ( Overseas Development Institute), Portland House, Stage Place, London SWIE 5DP, Final Report, June, 2000.

6- Ricardo Gottschalk, Growth and Poverty Reduction in Developing Countries; How much External Financing will be needed in the new Century?, project on Multilateral Development Banks Commissioned by the Ministry of Foreign Affairs of Sweden, institute of Development Studies, University of Sussex, Brighton, UK, December 2000.

7- Rashid Mehmood and Sara Sadiq, The Relationship between Government Expenditure and Poverty: A Cointegration Analysis, Romanian Journal of Fiscal Policy, Volume 1, ISSU 1, July-December 2010.

8- RS-Lecture 12, Heteroscedasticity,

https://www.bauer.uh.edu/rsusmel/phd/ec1-12.pdf

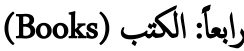

1. Damodar N. Gujarati, Basic Econometrics, Fourth Edition, the McGraw-

Hill Companies, 2004.

2. Daniel Ciuiu, Pattern Classification using Polynomial and Linear Regression”, Proceedings of the International Conference Trends and Challenges in Applied Mathematics, Technical University of Civil Engineering, Bucharest, Romania,2008.

3. Egbide Ben-Caleb, PUBLIC BUDGETING AND POVERTY REDUCTION IN NIGERIA, CUGP070187, JANUARY, 2015.

4. Jeffrey L.Esser, recommended budget practices and local government budgeting, printed in united states of America, second printing, June. 1999.

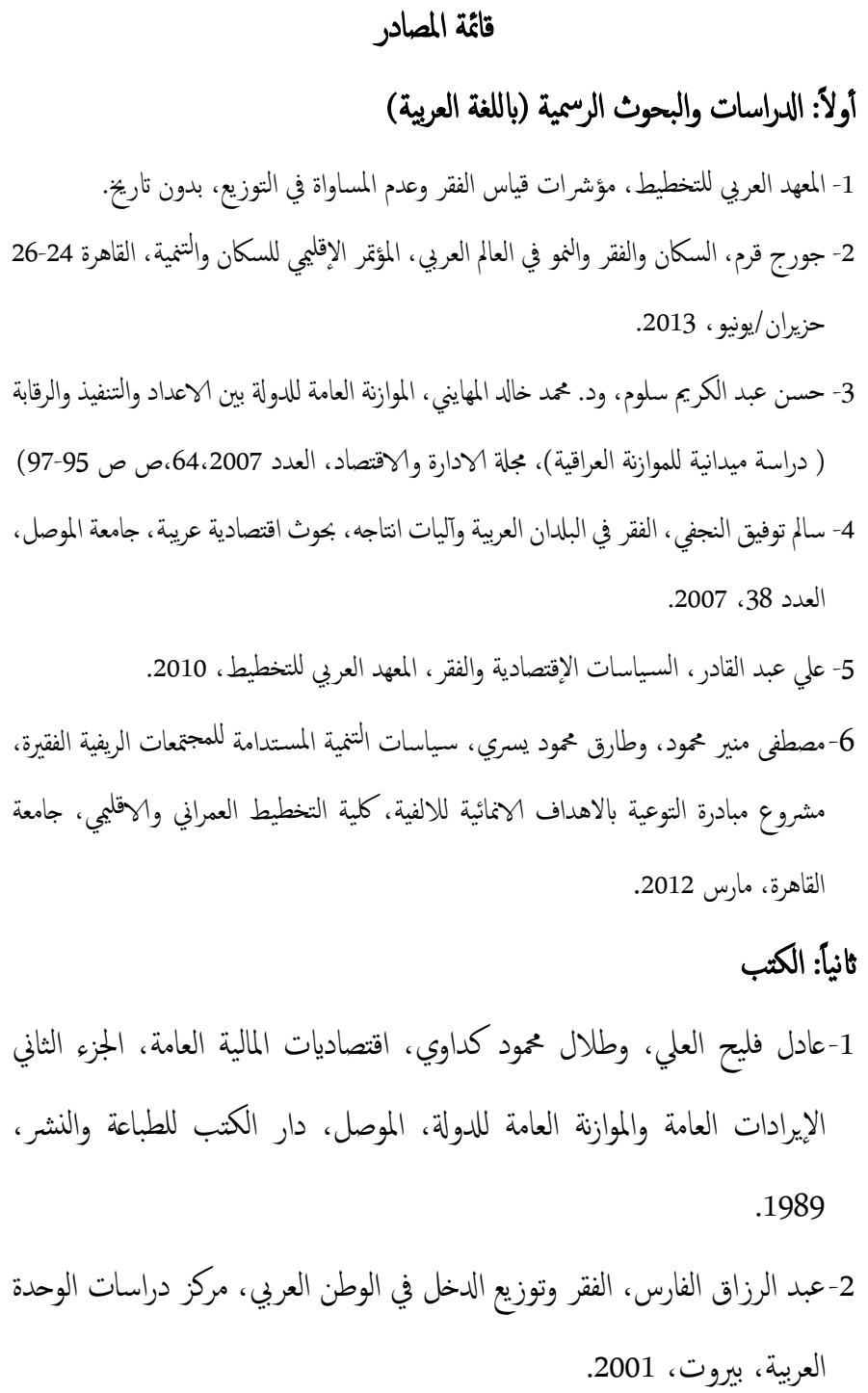

1- Shaheed Abrahams, Budgeting, forecasting and financial planning as a strategic tool in the eastern capes manufacturing industry, submitted in partial fulfillment of the requirements for the degree of magister technologiae; cost and management accounting at the nelson Mandela metropolitan university, November 2012.

2- Hashem Pesaran, General Diagnostic Tests for Cross Section Dependence in Panals, Discussion Paper No.1240, August 2004.

3- Nazar Dahmardeh \& Mahmoud Hashemi Tabar, Government Expenditures and its Impact on Poverty Reduction (Empirical from Sistan and Baluchestan Province of Iran), $\mathrm{HR}_{\mathrm{MARS}}$, International Journal of Academic Research in Economics and Management Sciences, January 2013, Vol. 2,No.1, ISSN: 2226-3624. 
5. Martin Ravallion, Shaohua Chen, What can new Survey data tell us about recent changes in distribution and poverty? World Bank Economic

\section{شكل (1) (نسبة الإنفاق على الثعليم من GDP)}



شكل (2) (نسبة الإنفاق على الصحة من GDP)



شكل (3) (نسبة الإنفاق العسكري من GDP)

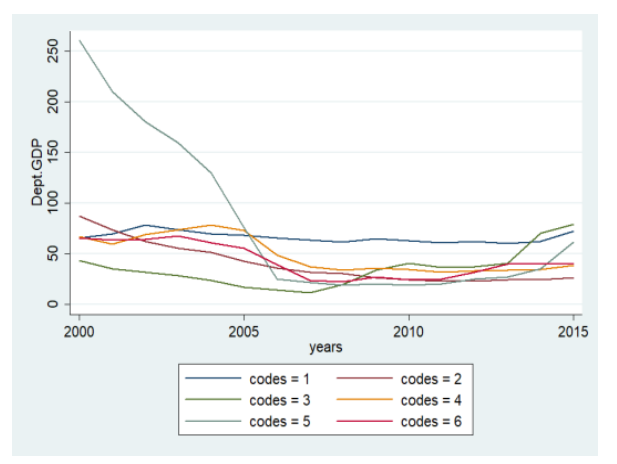

شكل (4) (نسبة الدين العام من GDP)

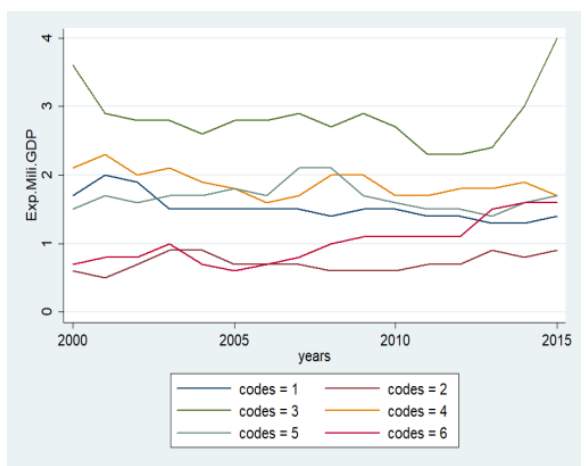

Review 11(2), 1997.

6. National Research Council , Population growth and economic development: policy question, 1986, Washington, DC: National Academy of Sciences. Committee on Population.

7. ILO NELSON ANAYO, Impact of Privatization of Public Enterprises on Poverty Reduction in Nigeria, A dissertation Submitted to the Department of Management, Faculty of Business Administration in Partial Fulfillment of the Requirements for the Award of Master of Business Administration(MBA) in Management, May, 2011.

8. Rafael E. De Hoyos \& Vasilis Sarafidis, Testing for Cross- Sectional dependence in Panel data models, The Stata Journal 2006, 6 Number.

9. Ron P. Smith, PANEL TIME-SERISE, Department of Economics Mathematics and Statistics, Birkbeck University of London, August 2016.

10. Tijo Birowo, Relationship between Government Expe nditure and Poverty Arte in Indonesia, APU, Research Report to Requirements for the Degree of Master of Science of International Cooperation Policy, Graduate School of Asia Pacific Studies Ritsumeikanasia Pacific University Japan, 2011.

11. UNDP, Human Development Report 2013, The Rise of the South: Human Progress in a Diverse World, Published for the United Nations Development Programmed (UNDP).

12. World Bank (OED), Morocco: Socioeconomic Impact of Rural Roads (Fourth Highway Project Loan 2254-MOR), Impact Evaluation Report No.15808. Washington, DC: World Bank, 1996.

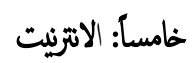

World bank : a puplic expenditure review, report $n^{\circ} 36270$,vol 1,2007,P4.( http://siteresources.worldbank.org/INTALGERIA/Resources/ALGERIAP ER_ENG_Volume_I.pdf 
شكل (5) (نسبة الإيرادات الضريبية من GDP)

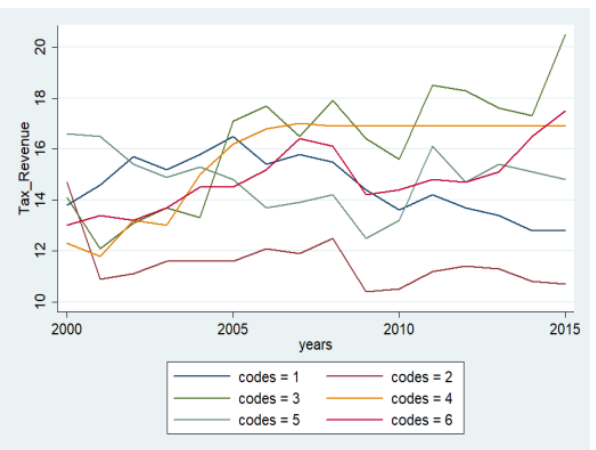

شكل (6) (خط الفقر الدولي \$1.90)

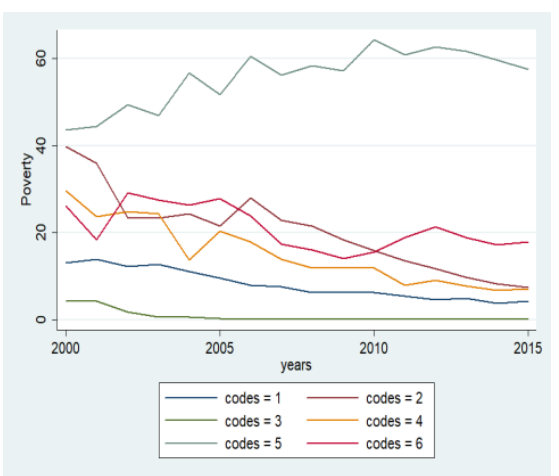

المصدر: من عمل الباحث بالإعتماد على بيانات البنك الدولي لعام 2018. حيث أن: codes=1 هي دولة اندونيسيا، codes=3 هي دولة بوليفيا، codes=4 codes=5 هي دولة زامبيا، هي دولة هندور اس. 